\title{
Dual roles of astrocytes in plasticity and reconstruction after traumatic brain injury
}

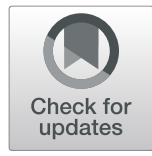

\author{
Yunxiang Zhou ${ }^{1+}$, Anwen Shao ${ }^{2^{*}+}$, Yihan Yao ${ }^{1}$, Sheng Tu ${ }^{3}$, Yongchuan Deng ${ }^{1}$ and Jianmin Zhang ${ }^{2}$
}

\begin{abstract}
Traumatic brain injury (TBI) is one of the leading causes of fatality and disability worldwide. Despite its high prevalence, effective treatment strategies for TBI are limited. Traumatic brain injury induces structural and functional alterations of astrocytes, the most abundant cell type in the brain. As a way of coping with the trauma, astrocytes respond in diverse mechanisms that result in reactive astrogliosis. Astrocytes are involved in the physiopathologic mechanisms of TBI in an extensive and sophisticated manner. Notably, astrocytes have dual roles in TBI, and some astrocyte-derived factors have double and opposite properties. Thus, the suppression or promotion of reactive astrogliosis does not have a substantial curative effect. In contrast, selective stimulation of the beneficial astrocytederived molecules and simultaneous attenuation of the deleterious factors based on the spatiotemporalenvironment can provide a promising astrocyte-targeting therapeutic strategy. In the current review, we describe for the first time the specific dual roles of astrocytes in neuronal plasticity and reconstruction, including neurogenesis, synaptogenesis, angiogenesis, repair of the blood-brain barrier, and glial scar formation after TBI. We have also classified astrocyte-derived factors depending on their neuroprotective and neurotoxic roles to design more appropriate targeted therapies.
\end{abstract}

Keywords: Astrocyte, Traumatic brain injury, Reconstruction, Neurogenesis, Blood-brain barrier, Glial scar

\section{Background}

Traumatic brain injury (TBI) refers to a sudden trauma caused by traffic accidents, wars, violence, terrorism, falls, and sporting activity [1]. TBI is currently the primary cause of human death in young adults and one of the leading causes of fatality and disability across all ages worldwide, resulting in annual global economic losses of amounting to $\$$ US400 billion [2-4]. The high mortality and morbidity of TBI and the substantial economic burden affect the patients, families, and society, and have attracted public attention [5]. To date, more than 1000 clinical trials on TBI have been registered on clinicaltri als.gov. In spite of the immense efforts on the treatment

\footnotetext{
*Correspondence: 21118116@zju.edu.cn; anwenshao@sina.com

${ }^{\dagger}$ Yunxiang Zhou and Anwen Shao contributed equally to this work.

${ }^{2}$ Department of Neurosurgery, The Second Affiliated Hospital, School of Medicine, Zhejiang University, Province, Zhejiang 310009, Hangzhou, China Full list of author information is available at the end of the article
}

of TBI made in the past few decades, few effective therapies for TBI are available [6-8].

One of the reasons for the failure is because most previous studies have targeted neuronal cells, whereas emerging evidence shows that glial cells also play significant roles in the pathogenesis of TBI [9-11]. Astrocytes, a type of glial cells, are involved in the homeostasis and blood flow control of the central nervous system (CNS) [12]. TBI is known to induce astrocyte activation (reactive astrogliosis), which is involved in tissue remodeling processes such as neurogenesis, synaptogenesis, repair of the blood-brain barrier (BBB), regulation of synaptic plasticity, and formation of glial scar and extracellular matrix (ECM), weighing a lot to the patient outcome [13-15]. However, reports on the effects of reactive astrogliosis are not consistent $[10,16-18]$. The current review summarizes the existing knowledge on the role of astrocytes in TBI. We particularly elaborate on the 
various roles of astrocytes and astrocytes-derived molecules in plasticity and reconstruction and explore the possibility of using astrocytes to optimize their therapeutic benefit while attenuating the harmful effects of them.

\section{Overview of TBI and astrocyte \\ Traumatic brain injury}

Traumatic brain injury is a prevalent disease, with a global annual burden of approximately $\$$ US400 billion [2, 3]. According to statistics by the World Health Organization, TBI affiliated mortalities and disability will surpass that of many diseases as from the year 2020 [19]. However, there are currently no effective therapies for TBI $[6,7]$. And the main form of clinical treatment is restricted to surgical interventions and supportive managements, including hyperbaric oxygen, task-oriented functional electrical stimulation, non-invasive brain stimulation, and behavioral therapy $[6,20]$. One of the main challenges of treating TBI is the heterogeneity of its pathologic and pathogenic mechanisms. Consequently, an in-depth elucidation of the underlying pathophysiological mechanisms is required to provide new therapeutic targets.

\section{The pathophysiology of TBI}

Traumatic brain injury is characterized by instant damage to mechanical force and delayed damage to the subsequent pathophysiological processes [21]. The mechanical force directly leads to neuronal or diffuse axonal damage and vascular disruption, followed by secondary injury mediated by extensive neuroinflammation, dysfunction of the BBB, oxidative stress, and apoptosis [22-26]. While the immediate primary injury is considered untreatable, the delayed secondary injury gives a window for intervention and has, therefore, attracted a lot of attention [27].

Following the initial injury, local environment changes and damaged cells release intracellular components, triggering the activation and recruitment of resident glial cells in the brain as well as the production of various cytokines, chemokines, and excitotoxins; then the peripheral immune cells are recruited into the brain with further release of signaling factors to induce a robust sterile immune reaction [28-30]. A broad range of literature data has reported the up-regulated expression of cytokines including interleukin (IL)-1 $\beta$, tumor necrosis factor (TNF)- $\alpha$, transforming growth factor- $\beta$ (TGF- $\beta$ ), interferon $\gamma$ (IFN $\gamma$ ), IL-6, IL-10 and IL-12 as well as the chemokines such as chemokine ( $\mathrm{C}-\mathrm{C}$ motif) ligand (CCL)2, CCL3, CCL4, chemokine (C-X-C motif) ligand (CXCL)1, CXCL2, CXXL4, CXCL8/IL-8 and CXCL10 in the early stages post-TBI, which boost the sterile inflammation [28, 31]. These lead to additional attraction of peripheral cells, continuous activation of resident glial cells, and aggravated neuronal damage [28, 32]. Disruption of the BBB integrity and the neurovascular unit (Fig. 1) can occur as a result of the initial injury or arise secondarily to the extensive neuroinflammation, astrocytic dysfunction, and metabolic disturbances. These damages result in vascular leakage, brain edema, cerebral hemorrhage, and hypoxia [27, 29, 33-35]. Neuronal apoptosis also significantly contributes to secondary injury $[36,37]$. In addition to apoptosis, necroptosis, a recently identified programmed cell death bearing resemblance to both apoptosis and necrosis, has also been demonstrated to play an indispensable role in secondary neuronal cell death and neuroinflammation postTBI $[38,39]$. Mechanically, upon pathogenic stimuli following TBI, TNF- $\alpha$-induced receptor-interacting protein 1 activation contributes to the formation of the so-called necrosome, a complex necessary for necroptosis [40, 41]. And after necroptosis, inflammatory factors released from damaged cells flow into the extracellular space, boosting the neuroinflammation [41-43]. All these primary or secondary pathologic mechanisms contribute to cell death, tissue loss, structural and metabolic abnormalities, and an ultimate neurological dysfunction in the patients [15, 44]. And whether neural structure and function can be restored determines the final outcome of the TBI patients [36].

\section{Astrocyte reaction after TBI onset}

Among brain resident glial cells such as astrocytes (astroglia), oligodendrocytes and microglia, astrocytes are the most abundant [45]. Astrocytes are characterized by the presence of glial fibrillary acidic protein (GFAP), a unique structural protein [45]. Under normal physiological conditions, astrocytes are involved in the homeostasis and blood flow control of the CNS [12]. Astrocytes structurally support neurons and separate the CNS from the meninges, blood vessels, and perivascular spaces by the creation of a functional barrier named glia limitans, which is formed via the interaction of astrocytic foot processes with the parenchymal basement membrane [46]. In addition, astrocytes provide functional support for neurons, including the recycling of the neurotransmitter glutamate, the most potent neurotoxin in the brain, via glutamate transporters (Fig. 2), the glutamate-glutamine shuttle system, and cystine-glutamate antiporter system [47-49]. Astrocytes play a role in the release of neurotrophic factors and gliotransmitters such as glutamate, ATP, $\gamma$-aminobutyrate (GABA), and D-serine $[1,15,50]$; the synthesis of glutamine, cholesterol, superoxide dismutases, glutathione, ascorbate and thrombospondin (TSP)- 1 and $2[9,51,52]$. Astrocytes are also involved in the regulation of energy metabolism by the conversion of glucose into lactate 


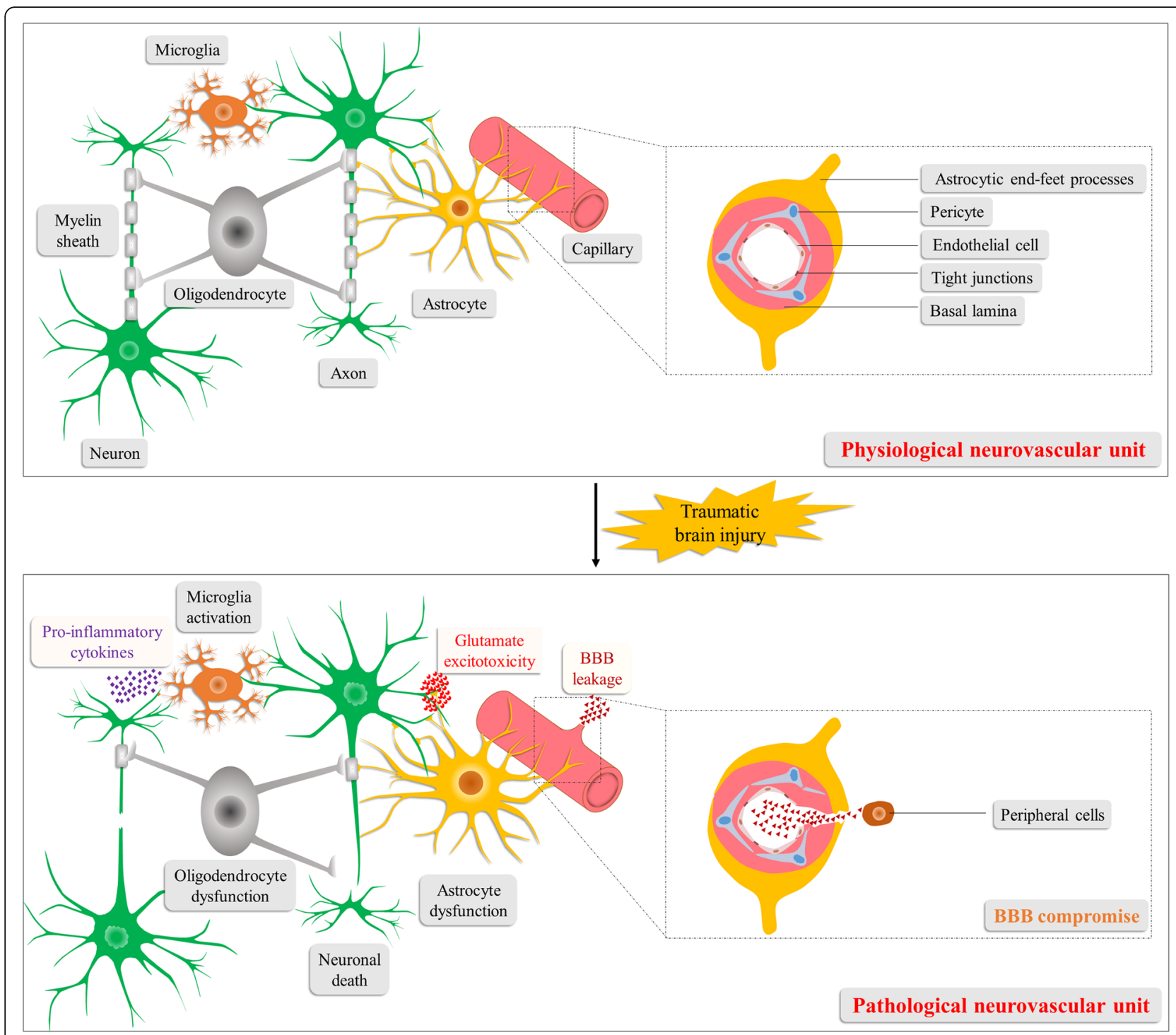

Fig. 1 Schematic illustration of the neurovascular unit under normal physiological conditions and TBI pathological conditions. The neurovascular unit encompasses neurons, glial cells (astrocytes, oligodendrocytes and microglia), vascular cells (pericytes, endothelial cells and vascular smooth muscle cells) and the basal lamina matrix. Following TBI, disruption of the neurovascular unit arises from and further aggravates the pathophysiological processes of TBI, which include BBB compromise, neuronal death, neuroglial dysfunction, neuroinflammation, and metabolic disturbances

[53-55] and the regulation of neuronal activation and water homeostasis through extracellular ion concentrations [56-59]. Given the multifunctional roles of astrocytes in the CNS, they can affect neuronal activity, modulate plasticity, and participate in CNS regeneration after brain injury [60-64].

Microglia are cells of myeloid origin and are considered "the CNS professional macrophages", which express a large repertoire of pattern-recognition receptors and are often the first cells responding to any inflammatory events $[29,65]$. Importantly, more and more lines of evidence suggests that astrocytes also express a series of receptors related to inflammatory and immune processes, including Toll-like receptors, purinergic receptors, mannose receptors, scavenger receptors, nucleotide-binding oligomerization domain proteins, double-stranded RNA dependent protein kinase, and components of the complement system, through which they sense a wide range of endogenous and exogenous signals and respond dynamically to sterile injuries and infectious non-self [29, 65-67]. Therefore, danger signals post-TBI can trigger inflammasomes and innate immune response via their interaction with the receptors on the innate immune neuroglia. Mechanically, when the local 


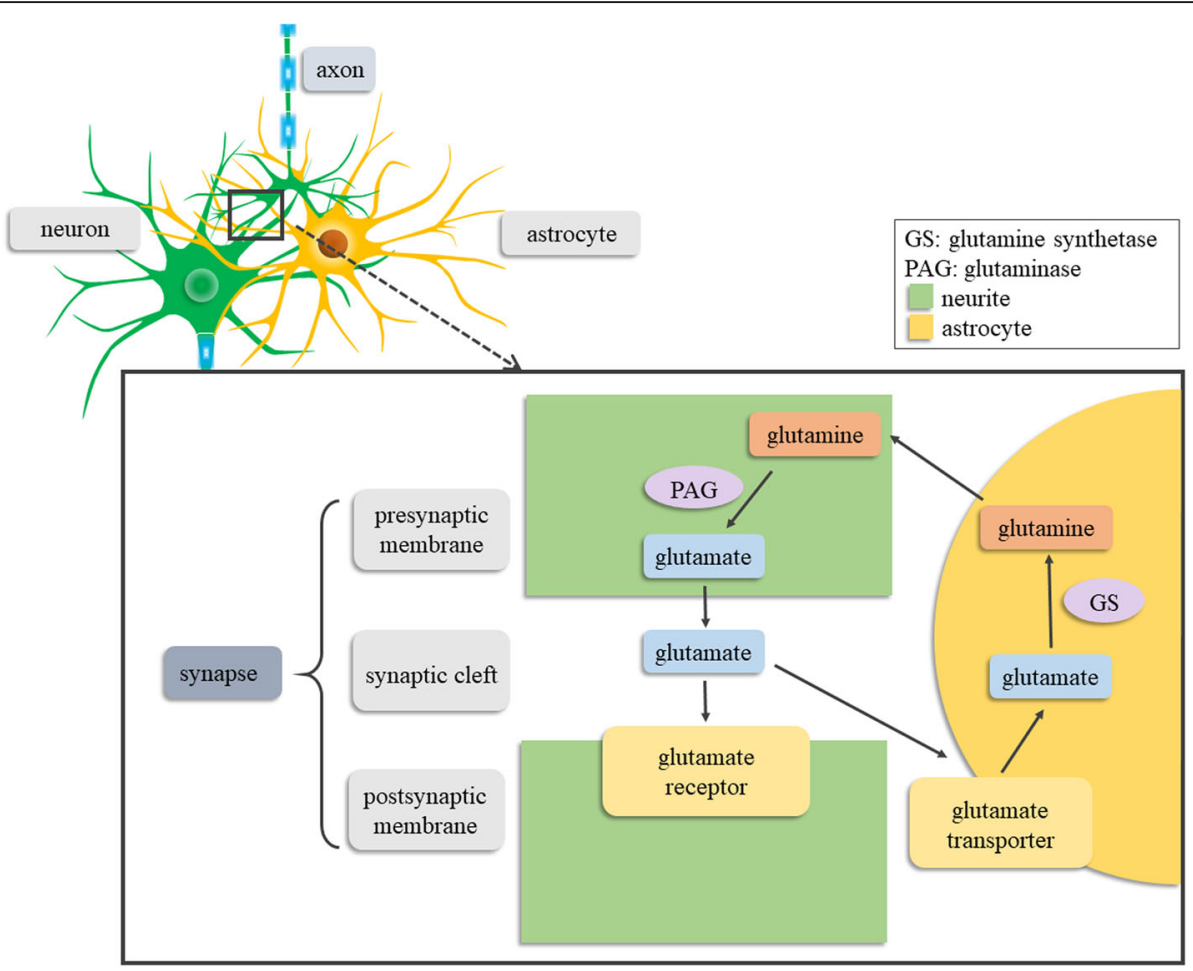

Fig. 2 Schematic illustration of the glutamate-glutamine cycle in astrocytes. Astrocytes play a crucial role in the glutamate cycle of glutamateglutamine. After the presynaptic membrane releases neurotransmitter glutamate, astrocytes can take in glutamate from the synaptic cleft through the glutamate receptor and synthesize glutamine with the catalysis of glutamine synthetase. And the glutamine can cross the cell membrane into the cytoplasm of presynaptic membrane and be deaminated by glutaminase to produce glutamate

biochemical environment changes following the onset of TBI, danger signals induce the structural and functional alterations of astrocytes, including hypertrophy and increased expression of the intermediate filaments (nestin, vimentin, and GFAP), resulting in astrocyte activation (reactive astrogliosis) $[15,68]$. Other cells such as brain-resident microglia are also activated [31]. Both astrocytes and microglia react within 24 hours and peak around day $3-7$, however, microglia rapidly decline to control levels approximately 21 days after the lesion while astrocytes exhibit a long-lasting proliferative response, at least, 28 days after TBI [69-71]. The activation and proliferation of glial cells, in turn, have utility in releasing signaling factors and triggering a robust sterile immune reaction that consists of brain-resident as well as peripherally recruited inflammatory cells. This reaction is initiated to exert neuroprotective effects and promote wound healing, but may become maladaptive over time $[29,72]$.

As the inflammatory response progresses, local astroglial progenitors around the injured tissue form the glial scar that isolates the damaged area, contains the spread of inflammatory cells, provides a favorable environment for surviving neurons, and maintains the integrity of the BBB $[46,68,73-75]$. Nonetheless, the glial scar is considered the main hindrance to axonal regeneration and recovery of neuronal connectivity [76, 77]. This shows one of the Janus-like effects of astrocytes. Controversy also remains as to whether reactive astrogliosis is beneficial for the maintenance of BBB integrity after TBI [21, 78], since astrocytes can largely affect BBB integrity and water homeostasis [79] as detailed below: (1) the BBB is sheathed by perivascular astrocyte foot processes [80]; (2) the glymphatic system is formed by astrocytes [81]; (3) the perivascular aquaporin-4 (AQP4) is densely and exclusively expressed in astrocyte end-feet [82]; (4) the permeability of the BBB can be affected by astrocyte-derived factors [78]; and (5) the concentration of extracellular ions is controlled by astrocytes [9]. These "irrational" phenomena can be caused by an overreaction and dysfunction of reactive astrocytes after brain injury, or due to the release of neurodeleterious molecules [78]. Astrocytes, therefore, hold both neuroprotective and neurodeleterious effects following TBI, making it a double-edged sword for neurorestoration [83-85]. This also indicates that we cannot simply suppress or promote reactive astrogliosis, but should selectively stimulate the beneficial effects and ameliorate the deleterious ones in the astrocytetargeting therapy [78]. 


\section{Dual roles of astrocytes in plasticity and reconstruction after TBI}

As previously mentioned, all the primary and secondary pathologic mechanisms underlying TBI contribute to cell death, tissue loss, structural and metabolic abnormality, and ultimately lead to neurological dysfunction of TBI patients $[15,44]$. And the ability to restore neural structure and function determine the outcome of the patients $[36,86]$. Thus, promoting the astrocytes/astrogliosis-induced neuroprotective effects/molecules or attenuating the neurodeleterious ones in terms of neuronal regeneration and tissue reconstruction may represent a promising therapeutic target for TBI. Below, we will describe the astrocytes and a range of astrocyte-derived molecules, as well as their roles in neurogenesis, synaptogenesis, angiogenesis, blood-brain barrier repair, and glial scar formation after neurotrauma.

\section{Neurogenesis}

Emerging evidence has indicated that astrocytes play a vital role in neurogenesis, which is attributed to the regulation of the microenvironment of neurogenic niche $[87,88]$.

\section{The neurogenesis-promoting effects of astrocytes}

Some studies suggested a beneficial effect of astrocytes in neurogenesis, both through the instruction of neuronal fate commitment and the promotion of proliferation of adult neural stem cells [88]. In addition, the neurogenesis-promoting effect of astrocytes has regional characteristics: hippocampal-derived astrocytes retain this potential, whereas astrocytes from the adult spinal cord do not [88]. Currently, some potential mechanisms concerning astrocytes-induced neurogenesis have been proposed. Astrocytes produce the neurotrophic and mitogenic protein S100 $\beta$ in vivo. Intraventricularly administration of $S 100 \beta$ enhances neurogenesis within the hippocampus and improves cognitive function recovery following TBI. These improvements are mediated by the facilitation of neuronal differentiation, proliferation, and survival of hippocampal progenitor cells [89, 90]. Heme oxygenase induced by astrocytes after TBI catalyzes heme to carbon monoxide (CO), ferrous iron, and biliverdin. Notably, low concentrations (lower than 250 ppm possibly) of $\mathrm{CO}$ exert promotive effects on neurogenesis, as well as synaptic plasticity and angiogenesis [91]. Moreover, previous studies reported that mature astrocytes might regress to an immature phenotype and show stem cell characteristics [92].

Besides stimulating stem cell genesis, astrocytes also contribute to the prolonged survival of newborn neurons [93]. Neurotrophic factors secreted by astrocytes are closely involved in neuronal support and survival, and intraperitoneal administration of a formulation composed of co-ultramicronized palmitoylethanolamide and luteolin was found to promote this process [94, 95]. Additionally, pituitary adenylate cyclase-activating peptide expressed by astrocytes plays a significant role in the support and survival of new neurons post-TBI [93]. Both the enhanced neurogenesis and long-lasting survival of newborn neurons result in a better neurological recovery.

\section{The neurogenesis-suppressing effects of astrocytes}

However, under certain pathological conditions, such as severe TBI with devastating excitotoxicity and inflammatory response, the microenvironment of neurogenic niche may lose its homeostasis [21, 96]. Correspondingly, some studies proposed that knockout/knockdown of molecules produced by astrocytes or suppression of astrocyte-related signaling enhances neurogenesis. Mice devoid of GFAP and vimentin are found to be developmentally normal with increased hippocampal neurogenesis and axonal regeneration post-TBI, despite that GFAP is essential for astrocyte activation and acute cellular stress handling [97-100]. This disparity may be due to the mechanism that differentiation of uncommitted neural progenitor cells is skewed towards neuronal lineage under the null of GFAP gene condition, and inhibition of Sirt1 expression may strengthen this inclination [101]. The effects and mechanisms of several GFAP suppressors have also been evaluated in experimental TBI [45].

Garber et al. revealed that astrocytes impaired neuronal progenitor cell homeostasis via the up-regulated expression of IL-1, thus hindering hippocampal neurogenesis in West Nile virus neuroinvasive disease, which could be reversed by IL-1R1 antagonist [83]. Upregulated IL-1 $\beta$ is also found to aggravate excitotoxicity and seizures post-TBI, although the latter can develop independently from the neurotoxic effects [102, 103]. Interestingly, Barkho et al. suggested that IL-1 $\beta$ and IL-6 could promote neuronal differentiation of neural stem/ progenitor cells at relatively low concentrations and thus they proposed a concentration-depending effect of astrocyte-derived pro-inflammatory cytokines. They also indicated that three other astrocyte-derived molecules: insulin-like growth factor (IGF) binding protein 6 and decorin, which inhibit IGF and TGF- $\beta$ respectively, and opioid receptor agonist enkephalin, could inhibit neurogenesis [104].

\section{Synaptogenesis}

Astrocytes also play a crucial role in synaptic plasticity, remodeling, and regeneration post-TBI $[105,106]$. As mentioned earlier, astrocytes are involved in the biochemical synthesis, metabolism, and secretion of many molecules. Some of these molecules, such as TSP-1 and 
TSP-2, promote synaptogenesis, while molecules, including trophic factors and cholesterol, preserve synapse maturation and maintenance [106-108]. Reversely, these mechanisms (and others) are also potentially critical for eliciting pathological responses during and after TBI $[87,109]$.

\section{The synaptogenesis-promoting effects of astrocytes}

Several studies have reported the beneficial role of astrocytes in synaptogenesis, which is reflected in its involvement in synaptic formation, metabolic support, and neurotransmitter release $[9,110]$. For instance, astrocytes regulate the expression and localization of agrin, one of matrix metalloproteinase (MMP)-3 substrates, which induces reactive synaptogenesis and neurological recovery [111]. And astrocytes support ovarian steroids estradiol-enhanced neurite outgrowth, although this can be antagonized by activated microglial-induced progesterone [112]. Remarkably, astrocytic signal transducer and activator of transcription-3 (STAT3) is capable to regulate the process formation and re-expression of TSP-1 of perineuronal astrocytes [18]. Furthermore, STAT3 supports neuronal integrity and mediates antiinflammatory reactions $[18,113,114]$. The augmentation of STAT3 discloses a neuroprotective effect, whereas the conditional ablation of STAT3 has the opposite effect [113, 114]. Nevertheless, Christopherson et al. demonstrated that TSP-induced excitatory synapses are postsynaptically silent, which owes to the lack of functional $\alpha$-amino-3-hydroxy-5-methyl-4-isoxazole propionic acid (AMPA) receptors [115]. Similarly, Kucukdereli et al. demonstrated that hevin, another matricellular protein secreted by astrocytes, could induce the same type of synapse as TSP [116]. On the contrary, the homologous sequence protein, secreted protein acidic and rich in cysteine (SPARC) inhibits hevin-induced synapse formation [116-118]. Other astrocyte-derived molecules such as glypicans [119], TGF- $\beta$ [120, 121], and brain-derived neurotrophic factor [122] can induce excitatory synapse formation, while $\gamma$-protocadherin can induce the formation of either excitatory or inhibitory synapse via a contact-dependent mechanism [123].

\section{The synaptogenesis-suppressing effects of astrocytes}

Following the breakdown of the BBB, an influx of serum elements, and the inflammatory cytokines, including IL1 , TGF- $\beta$ trigger the formation of a glial scar to cope with injury. Nonetheless, the glial scar is considered the main hindrance to axonal regeneration and neuronal connectivity recovery, due to the production of growthinhibitory components and the formation of physical and chemical barriers that hinder axon elongation [30, $76,77,124]$. Among the inhibitory components, chondroitin sulfate proteoglycans (CSPGs), one of the ECM molecules produced by astrocytes, are of prime importance as they are predominantly responsible for the nonpermissive characteristic of glial scar and have been extensively studied [125-128]. The major brain CSPGs include lecticans (neurocan, brevican, versican, and aggrecan), phosphacans, and transmembrane NG2; they surround and affect the perineuronal nets (PNNs), which are comprised of rich ECM and cell adhesion proteins and have been found to stabilize synapses $[129,130]$. The class IIa/Leukocyte common antigen-related (LAR) family [131] and the NOGO receptors NgR1 and NgR3 [132] have been identified as CSPG receptors and convey subsequent axonal growth inhibition. However, heparan sulfate proteoglycans (HSPGs), another ligand for the LAR family receptors promotes axon extension [133]. This role of HSPGs may result from the switch of axonal endings between states of growth and inactivity via the oligomerization status of PTPб (a member of the LAR family) [76]. Therefore, agents targeting these receptors or that mimic HSPG binding may mitigate the inhibitory environment of glial scar and augment neuronal regeneration, thus suggesting multiple candidates of therapeutic application for TBI [134, 135]. For instance, the hepatocyte growth factor, which exhibits pleiotropic functions in the CNS has been shown to suppress the expression of CSPGs after brain injury, as well as block the secretion of TGF- $\beta 1$ and $\beta 2$ and the subsequent induction of the glial scar [124]. Another ECM component, tenascin- $C$, was also shown to inhibit axon outgrowth and therefore represents a target for intervention [136, 137].

Matrix metalloproteinases cleave ECM and are involved in the modulation of synaptogenesis. However, the definite role of MMPs in neurological recovery postTBI remains elusive, since it depends on where and when it is activated [138]. After severe TBI, astrocytes induce the expression of MMP-3 in a higher and more persistent pattern, resulting in maladaptive synaptogenesis and poor recovery of neural function, while MMP inhibitor FN-439 is shown to attenuate the activity of MMP-3 and then facilitate functional recovery [139]. Moreover, persistent expression of another MMP, $a$ distintegrin and metalloproteinase-10 (ADAM-10), parallels the attenuation of the $\mathrm{N}$-cadherin level, which is critical to synapse stability, and consequently contributing to reduced functional recovery; whereas inhibition of MMP shifts the expression of ADAM-10 and N-cadherin towards an adaptive pattern and facilitates the synapse formation [17].

\section{Synaptic plasticity}

In addition to the number of synapses, synaptic plasticity is also necessary for learning and memory formation. Synaptic plasticity can be influenced by activation and 
localization of glutamate receptor, synaptic strength, intracellular calcium levels, neurotrophic factors, and cytokines following TBI [140-142]. Considering the involvement of astrocytes in the pathophysiological processes including supporting neuronal metabolism, secreting different molecules that induce the formation of excitatory synaptic structure and function, and releasing gliotransmitters that affect the balance of neural network as well as synaptic potentiation or depression, astrocyte may be a promising target for modulating synaptic plasticity [87]. Following TBI, the general role of astrocytes in synaptic plasticity again remains obscure. For instance, the sphingosine 1-phosphate (S1P) receptor 1 antagonist siponimod preserves neural plasticity via attenuating activation of astrocytes, microglia, and other inflammatory cells [143]. On the contrary, minocycline influences neuronal plasticity and improves neurological recovery by increasing the astrogliosis following experimental stroke [144].

\section{The synaptic stability-promoting effects of astrocytes}

The previously mentioned neurogenesis-promoting $\mathrm{CO}$ also facilitates synaptic plasticity [91]. Besides, the synaptogenic factor TSP-1 can also suppress MMP-9-induced cleavage of extracellular matrix molecules and synaptic instability $[145,146]$. AQP4, which is the main water channel of astrocytes and exclusively expressed on astrocytes, plays a critical role in synaptic plasticity and memory encoding [147]. Moreover, AQP4 is also highly correlated with the balance of water, the function of glymphatic pathway and the integrity of the BBB while the role of AQP4 may, however, depend on the stage of TBI progression $[147,148]$. The study by Zhang et al. revealed that lack of AQP4 could lead to the accumulation and removal of excess water in the brain during acute and late stages of TBI, respectively [149], making AQP4-targeting therapy a great challenge.

Although the glial scar is regarded as the main impediment to axonal regeneration and neuronal connectivity recovery, it initially acts as a barrier isolating the damaged area, containing the spread of inflammatory cells, providing a favorable environment for surviving neurons and maintaining the BBB [30, 76, 150, 151]. Moreover, despite the detrimental roles mentioned above, CSPGs may help restrict inflammation by shifting monocytes towards resolving phenotype and enhancing the expression of anti-inflammatory cytokines, such as IL-10, as well as help stabilize the ionic microenvironment by limiting diffusion of cations, such as potassium, calcium, and sodium [152, 153]. Furthermore, CSPGs [154, 155] and TNF- $\alpha$ [156-158] have been demonstrated to alter the level or mobility of AMPA receptors in a beneficial manner, which are critical in synaptic plasticity. Consistent with these findings, several studies have reported that most of the ECM molecules produced by astrocytes elicit both restrictive and permissive effects on axonal sprouting post-lesion [79]. Indeed, studies demonstrated that ablation of astrogliosis in transgenic mice disrupted scar formation, which in turn exacerbated the spread and persistence of inflammation response, vasogenic edema, neuronal loss, demyelination, and functional recovery [159-162]. Furthermore, blocking scar formation in STAT3 deletion mice has similar effects of inducing extensive lesions and increasing neuronal loss and locomotor deficits after CNS injury, while enhancing scar formation in protein suppressor of cytokine signaling 3 deletion mice has the opposite effects [113, 114]. These findings strongly suggest that astrogliosis and glial scar formation may be neuroprotective against brain damage under particular circumstances, highlighting a dichotomous role again.

\section{The synaptic stability-suppressing effects of astrocytes}

Astrocytes play a crucial role in regulating excitatory chemical transmission via glutamate transporters (Fig. 2), glutamate-glutamine shuttle system, and cystine-glutamate antiporter system. However, the impairment of astrocytic glutamate uptake and GABA release lead to glutamate excitotoxicity as well as ion and water imbalance post-TBI $[1,9]$. Glutamate is the primary excitatory neurotransmitter and the most potent neurotoxin once concentrated in the extracellular space of CNS. Notably, the homeostasis of glutamate is closely associated with synaptic plasticity [47-49]. Ephrin-A3, a member of the ephrin family, is expressed in astrocytes and is involved in the regulation of glial glutamate transporters. EphrinA3 is required for maintenance of long-term potentiation via its interaction with the A-type Eph receptor, namely EphA4, and thus influences synaptic plasticity. Once Ephrin-A3 is over-expressed following TBI, it decreases glutamate transporters and increases glutamate excitotoxicity, hence prolonging neuronal depolarization and focal dendritic swelling [163-165]. Therefore, inhibition of Ephrin-A3 represents a potential therapeutic strategy. Besides, the glutamate receptor antagonist MK801 has also been shown to enhance synaptic integrity and improve cognitive outcomes [138, 139].

Traumatic brain injury constitutes one of the most common causes of acquired epilepsy [166]. Epileptogenesis can be induced by several pathological processes, including glial scar, ECM remodeling, axonal plasticity alteration, excitation/inhibition imbalance, cell death, and neuronal heterotopia [167]. Once the structural integrity of PNNs is compromised by astrocyte-derived ECM molecules, dysfunctional PNNs around the fastspiking inhibitory interneurons might underlie excitation/inhibition imbalance and lead to the development of post-traumatic epilepsies [168]. The involvement of 
hyperphysiologic TNF- $\alpha$ in post-traumatic epileptogenesis has also been revealed $[169,170]$. In addition to its influences on glutamatergic transmission and synaptic plasticity, TNF- $\alpha$ also has an important role in the initial activation of microglia and astrocytes and the disruption of the BBB; and the biologic TNF antagonist etanercept was shown to improve the outcomes of experimental TBI [171]. Furthermore, astrogliotic upregulation of enzyme adenosine kinase also contributes to epileptogenesis [172]. Notably, TBI is also an important risk factor for the development of many neurodegenerative diseases such as Alzheimer's disease, chronic traumatic encephalopathy, amyotrophic lateral sclerosis, and etcetera; the deposition and accumulation of amyloid-beta and tau are considered as part of the pathological mechanisms [173-176].

\section{BBB repair}

Although TBI-induced astrogliosis and glial scar seem to promote the BBB repair [30], astrocytic dysfunction is one of the main pathological mechanisms giving rise to the BBB disruption post-TBI $[27,29,33]$. The dual roles of reactive astrogliosis owe to the distinct functions of various astrocyte-derived molecules in BBB integrity [78] (Table 1). Furthermore, these astrocyte-derived factors also regulate cell adhesion molecules on the endothelial cells, thereby controlling the leukocyte infiltration influx to the CNS, and participate in one or more pathophysiological processes including angiogenesis, neurogenesis, and neuroplasticity [78].

\section{The BBB integrity-promoting effects of astrocytes}

The integrity of the BBB is determined by the endothelial tight junctions and the basal lamina. While endothelial tight junctions are formed by proteins such as claudin, occludin and zonula occluden ( $\mathrm{ZO})$, the basal lamina forms the basement membrane of ECM and includes laminin, collagen, and fibronectin [177, 178]. Astrocyte-derived factors including angiopoietin-1 (ANG-1) [179-181], sonic hedgehog (SHH) [182-185], glial-derived neurotrophic factor (GDNF) [186-188], retinoic acid (RA) [189-191], and IGF-1 [192, 193] have been demonstrated to promote recovery of the BBB by protecting endothelial cells and/or enhancing tight junction reassembly, via signaling mediated by their receptors, tie-2, patched-1, GDNF receptor alpha-1 and alpha-2, nuclear RA receptor, and IGF-1 receptor, respectively [78, 79] (Table. 1). Besides, the astrocytesecreted apolipoprotein E (APOE) isoforms APOE2, APOE3, and APOE4, are also closely involved in the regulation of BBB integrity [194]. Notably, APOE exerts its regulation in an isoform-dependent manner [195]. Despite that APOE3 protects against BBB disruption via the suppression of a cyclophilin A (CypA)-nuclear factor- $\mathrm{kB}$ (NFkB)-MMP-9 pathway, APOE4 activates the pathway and results in neuronal dysfunction and degeneration [196]. Overall, APOE tends to maintain BBB integrity and promote neurological recovery. While APOE-deficiency provokes BBB dysfunction, exogenously administered APOE or its mimetic peptides preserve BBB integrity in experimental studies [197-203].

\section{The BBB integrity-suppressing effects of astrocytes}

Despite that some astrocyte-derived factors maintain the $\mathrm{BBB}$ function, some astrocyte-derived factors damage the $\mathrm{BBB}$ by inducing endothelial cell apoptosis or decreasing the expression of endothelial tight junctionrelated proteins, which include vascular endothelial growth factor (VEGF) [204-207], glutamate [208-210], endothelins (ETs) [21, 211, 212], MMP [208, 213, 214], and nitric oxide (NO) [215, 216] (Table 1). As zincendopeptidases, MMPs can directly degrade endothelial tight junction-related proteins and ECM molecules, which promotes angiogenesis whereas simultaneously increases BBB permeability [78, 217, 218]. And it is through the signaling pathway activating or suppressing MMPs that many other factors such as APOE, NO, and ETs get to affect the BBB integrity [201, 212, 215]. Although both $\mathrm{NO}$ and glutamate can decrease endothelial tight junction-related proteins, NO may have inconsistent effects on apoptosis through different pathways [219]. Furthermore, glutamate also exacerbates vascular permeability via the activation of glutamate receptors [220], and cytokines such as TNF- $\alpha$ are strictly related to BBB disruption [171, 211, 221].

The study by Prager et al. indicates that S1P binds to and activates five G protein-coupled receptors. Among these receptors, S1P receptor 1 (S1PR1) primarily preserves $\mathrm{BBB}$ integrity while the S1P receptor 2 damages integrity [222] and correspondingly, agents activating S1PR1 such as artesunate and isoflurane have been demonstrated to preserve the BBB integrity [223, 224]. However, several antagonists which suppress the activation of S1PR1 have also been found to preserve the BBB integrity [143, 222]. Remarkably, the S1PR1 antagonist fingolimod (FTY720) can also possibly induce S1P1 activation [225]. These observations suggest that S1PR1 plays a dual role in BBB permeability, depending on the ligand, which is in line with the assumption proposed by Schuhmann et al. [226].

\section{Usage of astrocyte and astrocyte-derived molecules as therapeutic targets}

As a result, all of the described neuroprotective and neurodeleterious molecules, as well as their upstream and downstream factors, represent potential therapeutic targets (Fig. 3 and Table 1). However, both astrocytes and astrocyte-derived molecules can only act as targets for particular subtypes, specific damage regions, and certain 
Table 1 Dual roles of astrocyte-derived factors in the BBB integrity after TBI

\begin{tabular}{|c|c|c|c|c|c|c|c|}
\hline $\begin{array}{l}\text { Astrocyte- } \\
\text { derived } \\
\text { factors }\end{array}$ & Characters & Receptors & $\begin{array}{l}\text { Role in } \\
\text { BBB } \\
\text { post-TBI }\end{array}$ & Mechanisms & Related agents & Other functions & References \\
\hline ANG-1 & Glycoprotein & Tie-2 & Protect & $\begin{array}{l}\text { Promote endothelial cells, } \\
\text { vascular remodeling, and } \\
\text { stability; increase TJ- } \\
\text { related proteins }\end{array}$ & $\begin{array}{l}\text { Exogenous ANG-1 or ANG- } \\
1 \text { mimetic peptides }\end{array}$ & $\begin{array}{l}\text { Promote angiogenesis; } \\
\text { suppress VEGF-induce ex- } \\
\text { pression of cell adhesion } \\
\text { molecules and leukocyte } \\
\text { infiltration }\end{array}$ & 179-181 \\
\hline $\mathrm{SHH}$ & Glycoprotein & Patched-1 & Protect & $\begin{array}{l}\text { Attenuate endothelial cells } \\
\text { apoptosis; increase TJ- } \\
\text { related proteins }\end{array}$ & Exogenous SHH & $\begin{array}{l}\text { Promote angiogenesis; } \\
\text { promote normal pattern } \\
\text { formation and cellular } \\
\text { differentiation in the } \\
\text { developing CNS; suppress } \\
\text { cell adhesion molecules } \\
\text { expression and leukocyte } \\
\text { infiltration }\end{array}$ & $182-185$ \\
\hline GDNF & $\begin{array}{l}\text { Neurotrophic } \\
\text { factor }\end{array}$ & $\begin{array}{l}\text { GDNF } \\
\text { receptor a- } \\
1 \text { and }-2\end{array}$ & Protect & $\begin{array}{l}\text { Increase TJ-related } \\
\text { proteins }\end{array}$ & Exogenous GDNF & $\begin{array}{l}\text { Promote the normal } \\
\text { postnatal development of } \\
\text { BBB, neuronal survival and } \\
\text { angiogenesis; axon } \\
\text { guidance and synapse } \\
\text { formation; control } \\
\text { endothelial functions; }\end{array}$ & $186-188$ \\
\hline RA & $\begin{array}{l}\text { Active } \\
\text { metabolite } \\
\text { synthesized } \\
\text { from retinol by } \\
\text { retinaldehyde } \\
\text { dehydrogenase }\end{array}$ & $\begin{array}{l}\text { Nuclear RA } \\
\text { receptors }\end{array}$ & Protect & $\begin{array}{l}\text { Increase TJ-related pro- } \\
\text { teins and vascular endo- } \\
\text { thelial cadherin }\end{array}$ & Exogenous RA & $\begin{array}{l}\text { Promote growth and } \\
\text { development in the CNS; } \\
\text { regulate synaptic } \\
\text { plasticity; suppress the } \\
\text { expression of cell } \\
\text { adhesion molecules }\end{array}$ & 189-191 \\
\hline IGF-1 & $\begin{array}{l}\text { A member of } \\
\text { insulin gene } \\
\text { family }\end{array}$ & $\begin{array}{l}\text { IGF-1 } \\
\text { receptors }\end{array}$ & Protect & $\begin{array}{l}\text { Attenuate endothelial cells } \\
\text { apoptosis }\end{array}$ & Exogenous IGF-1 & $\begin{array}{l}\text { Promote neurogenesis; } \\
\text { reduce cell death; support } \\
\text { injury repair; regulate } \\
\text { synaptic neuroplasticity }\end{array}$ & $\begin{array}{l}78,192 \\
193\end{array}$ \\
\hline APOE & $\begin{array}{l}\text { A member of } \\
\text { the } \\
\text { apolipoprotein } \\
\text { family }\end{array}$ & 1 & Protect* & $\begin{array}{l}\text { Suppress the activity of } \\
\text { MMP-9; increase TJ-related } \\
\text { proteins }\end{array}$ & $\begin{array}{l}\text { APOE-mimetic peptide } \\
\text { COG1410 }\end{array}$ & $\begin{array}{l}\text { Support lipid transport } \\
\text { and injury repair }\end{array}$ & $194-203$ \\
\hline VEGF & $\begin{array}{l}\text { An } \\
\text { angiogenetic } \\
\text { factor }\end{array}$ & $\begin{array}{l}\text { VEGFR-1 } \\
\text { and } \\
\text { VEGFR-2 }\end{array}$ & Damage & $\begin{array}{l}\text { Decrease TJ-related } \\
\text { proteins }\end{array}$ & $\begin{array}{l}\text { SU5416 (VEGFR-2 } \\
\text { inhibitor); cavtratin (a } \\
\text { selective inhibitor of VEGF- } \\
\text { A) }\end{array}$ & $\begin{array}{l}\text { Promote endothelial } \\
\text { proliferation and } \\
\text { differentiation for } \\
\text { angiogenesis; induce cell } \\
\text { adhesion molecules } \\
\text { expression and leukocyte } \\
\text { infiltration }\end{array}$ & $204-207$ \\
\hline MMP & $\begin{array}{l}\text { Zinc- } \\
\text { endopeptidases }\end{array}$ & 1 & Damage & $\begin{array}{l}\text { Enhance endothelial cell } \\
\text { apoptosis; degrade TJ- } \\
\text { related proteins and ECM } \\
\text { molecules }\end{array}$ & $\begin{array}{l}\text { Ro32-3555 (a broad } \\
\text { spectrum MMP inhibitor) }\end{array}$ & $\begin{array}{l}\text { Promote angiogenesis; } \\
\text { regulate expression of cell } \\
\text { adhesion molecules and } \\
\text { subsequent leukocyte } \\
\text { infiltration }\end{array}$ & $\begin{array}{l}208,213 \\
214\end{array}$ \\
\hline NO & $\begin{array}{l}\text { A potent } \\
\text { vasodilator } \\
\text { synthesized } \\
\text { from L-arginine } \\
\text { by NO synthase }\end{array}$ & 1 & Damage & $\begin{array}{l}\text { Enhance MMPs activation; } \\
\text { decrease TJ-related pro- } \\
\text { teins; induce apoptosis } \\
\text { through cGMP } \\
\text { monophosphate- } \\
\text { independent pathways, } \\
\text { suppress apoptosis } \\
\text { through cGMP pathway }\end{array}$ & $\begin{array}{l}\text { Nomega-Nitro-L-arginine } \\
\text { methyl ester (a non- } \\
\text { specific NOS inhibitor) }\end{array}$ & $\begin{array}{l}\text { Regulate blood flow for } \\
\text { neuronal activity; } \\
\text { exacerbate inflammatory } \\
\text { reaction }\end{array}$ & $\begin{array}{l}78,215 \\
216\end{array}$ \\
\hline Glutamate & $\begin{array}{l}\text { A major } \\
\text { excitatory } \\
\text { transmitter and }\end{array}$ & $\begin{array}{l}\text { NMDA } \\
\text { receptor } \\
\text { and the } \\
\text { AMPA } \\
\text { receptor }\end{array}$ & Damage & $\begin{array}{l}\text { Induce excessive vascular } \\
\text { permeability via activation } \\
\text { of NMDA receptors; } \\
\text { decrease TJ-related } \\
\text { proteins }\end{array}$ & $\begin{array}{l}\text { MK-801 (non-competitive } \\
\text { NMDA receptor } \\
\text { antagonist); CGS-19755 } \\
\text { (competitive NMDA recep- } \\
\text { tor antagonist); NBQX, } \\
\text { DNQX (competitive AMPA } \\
\text { receptor antagonists)** }\end{array}$ & $\begin{array}{l}\text { Regulate synaptic } \\
\text { plasticity and formation; } \\
\text { induce vasodilatation; } \\
\text { regulate neuronal survival }\end{array}$ & $208-210$ \\
\hline
\end{tabular}


Table 1 Dual roles of astrocyte-derived factors in the BBB integrity after TBI (Continued)

\begin{tabular}{|c|c|c|c|c|c|c|c|}
\hline $\begin{array}{l}\text { Astrocyte- } \\
\text { derived } \\
\text { factors } \\
\end{array}$ & Characters & Receptors & $\begin{array}{l}\text { Role in } \\
\text { BBB } \\
\text { post-TBI }\end{array}$ & Mechanisms & Related agents & Other functions & References \\
\hline$\overline{\mathrm{ETS}}$ & $\begin{array}{l}\text { Potent } \\
\text { endogenous } \\
\text { vasoconstrictors }\end{array}$ & $\begin{array}{l}\text { Endothelin } \\
\text { receptor } \\
\text { type A/B }\end{array}$ & Damage & $\begin{array}{l}\text { Exacerbate BBB } \\
\text { inflammation; enhance } \\
\text { MMPs activation; degrade } \\
\text { TJ-related proteins }\end{array}$ & $\begin{array}{l}\text { S-0139 (selective ETA } \\
\text { receptor antagonist); } \\
\text { BQ788 (selective ETB } \\
\text { receptor antagonist) }\end{array}$ & $\begin{array}{l}\text { Induce expression of cell } \\
\text { adhension molecules; } \\
\text { regulate endothelial } \\
\text { function }\end{array}$ & $\begin{array}{l}21,211 \\
212\end{array}$ \\
\hline S1P & $\begin{array}{l}\text { A biologically } \\
\text { active lipid }\end{array}$ & S1PR 1-5 & Dual & $\begin{array}{l}\text { Regulate VEGF activation } \\
\text { and TJ-related proteins }\end{array}$ & $\begin{array}{l}\text { Siponimod, fingolimod, } \\
\text { TASP0277308 (antagonists } \\
\text { of S1PR 1); artesunate, } \\
\text { isoflurane (agonists of } \\
\text { S1PR 1) }\end{array}$ & $\begin{array}{l}\text { Regulate synaptic } \\
\text { plasticity }\end{array}$ & $\begin{array}{l}143,222- \\
226\end{array}$ \\
\hline
\end{tabular}

\footnotetext{
${ }^{*}$ APOE exerts its regulation of BBB integrity in an isoform-dependent manner, APOE4 activates the activity of MMP-9 and accelerates the BBB permeability ${ }^{195,} 196$ * Some studies suggested that blockade of AMPA receptor did not promote glutamate-mediated BBB breakdown ${ }^{210}$

${ }^{\dagger}$ Both the antagonists which suppress the activation of S1PR 1 and agonists which activate S1PR 1 have been demonstrated to preserve the BBB integrity ${ }^{143,222-226}$

Abbreviations: ANG-1 angiopoietin-1, TJ tight junction, VEGF vascular endothelial growth factor, BBB blood-brain barrier, TBI traumatic brain injury, SHH sonic hedgehog, GDNF glial-derived neurotrophic factor, RA retinoic acid, IGF-1 insulin-like growth factor-1, $A P O E$ apolipoprotein $\mathrm{E}, M M P$ matrix metalloproteinases, $E C M$ extracellular matrix, NO nitric oxide, CGMP cyclic guanosine, NMDA N-methyl-D-aspartate, ETs endothelins, S1P sphingosine 1-phosphate, AMPA a-amino-3-hydroxy5-methyl-4-isoxazolepropionic acid, S1PR S1P receptor
}

stages of TBI. Therefore, therapeutic strategies must focus on the enhancement of neuroprotective effects and blockage of the neurodeleterious effects of the different factors under specific conditions.

Besides targeting astrocyte-derived molecules, stimulating the function of astrocyte-related receptors is also promising for the restoration of neuronal plasticity and reconstruction. Some astrocyte-derived molecules such as S1P and ETs also act as ligands of astrocytic receptors, and the probable therapeutic drugs are shown in the Table 1. Other receptors such as Toll-like receptors [127], purinergic receptor [227], glutamate receptor [228], hormone receptor [10, 229], and cannabinoid receptor [230] have also attracted widespread attention. Although we previously mentioned that MK-801, one of the glutamate receptor antagonists, had been shown to enhance synaptic integrity and improve cognitive outcome in the experimental study; but regrettably, clinical trials concerning the glutamate receptor antagonists have been widely carried out but failed to provide a statistically significant benefit for TBI patients [231]. According to Ikonomidou et al., the failure could be attributed to the attenuation of synaptic transmission, which impedes neuronal survival [228].

Modulating the maladaptive microenvironment post-TBI is also a considerable therapeutic strategy [140-142]. Relevantly, agents for reducing the glutamate excitotoxicity by enhancing glutamate transporters such as parawexin 1 and certain $\beta$-lactam antibiotics could be of therapeutic benefit [232, 233]. Other potential therapeutic mediators include agents for the restoration of ionic and water balance by targeting $\mathrm{Na}^{+} / \mathrm{H}^{+}$transporters, $\mathrm{Na}^{+} / \mathrm{K}^{+} / 2 \mathrm{Cl}^{-}$cotransporters, or $\mathrm{Na}^{+} / \mathrm{Ca}^{+}$exchangers such as fluorenyl drugs $[234,235]$ and agents that promote neuronal survival and function such as recombinant neurotrophins or peptidomimetics [9]. Agents that alter the lesion environment by modulating inflammatory responses such as minocycline and etanercept have also been proposed as potential candidates for neuroprotection [144, 171].

We have previously reviewed the advance of stem cell treatment for TBI, which has not reached a general success in clinic application [86]. Given the vital roles of astrocyte-secreted factors in the neurogenesis and neural differentiation, a combination of stem cell treatment and astrocytic functions may present a novel therapeutic strategy. Besides, non-coding RNAs also hold therapeutic potential as astrocytes express various non-coding RNAs, which in turn control astrocytic functions [236238]. And hypertonic saline has been found to elicit neuroprotection by regulating the expression of non-coding RNAs [239].

\section{Conclusion and perspectives}

In this article, we describe for the first time the detailed dual roles of astrocytes in the field of neuronal plasticity and reconstruction including neurogenesis, synaptogenesis, angiogenesis, BBB repair, glial scar formation after TBI, and attempt to classify astrocyte-derived factors by neuroprotection and neurotoxicity to make the targeted therapy more relevant and meaningful. However, not only astrocytes have a dual role, but some factors derived from astrocytes also have double-sided properties, which may due to the distinct microenvironment and molecular mechanisms underlying the different subtypes, different damage zone, and different stages of neurotrauma. For example, mild TBI and severe TBI will induce different physiological and pathological mechanisms as well as different astrocytic reaction; hippocampus-derived astrocytes and spinal cord-derived astrocytes boost different effects on neurogenesis; the acute and the late stages post-TBI elicit different roles of AQP4. Therefore, simply suppressing or promoting 


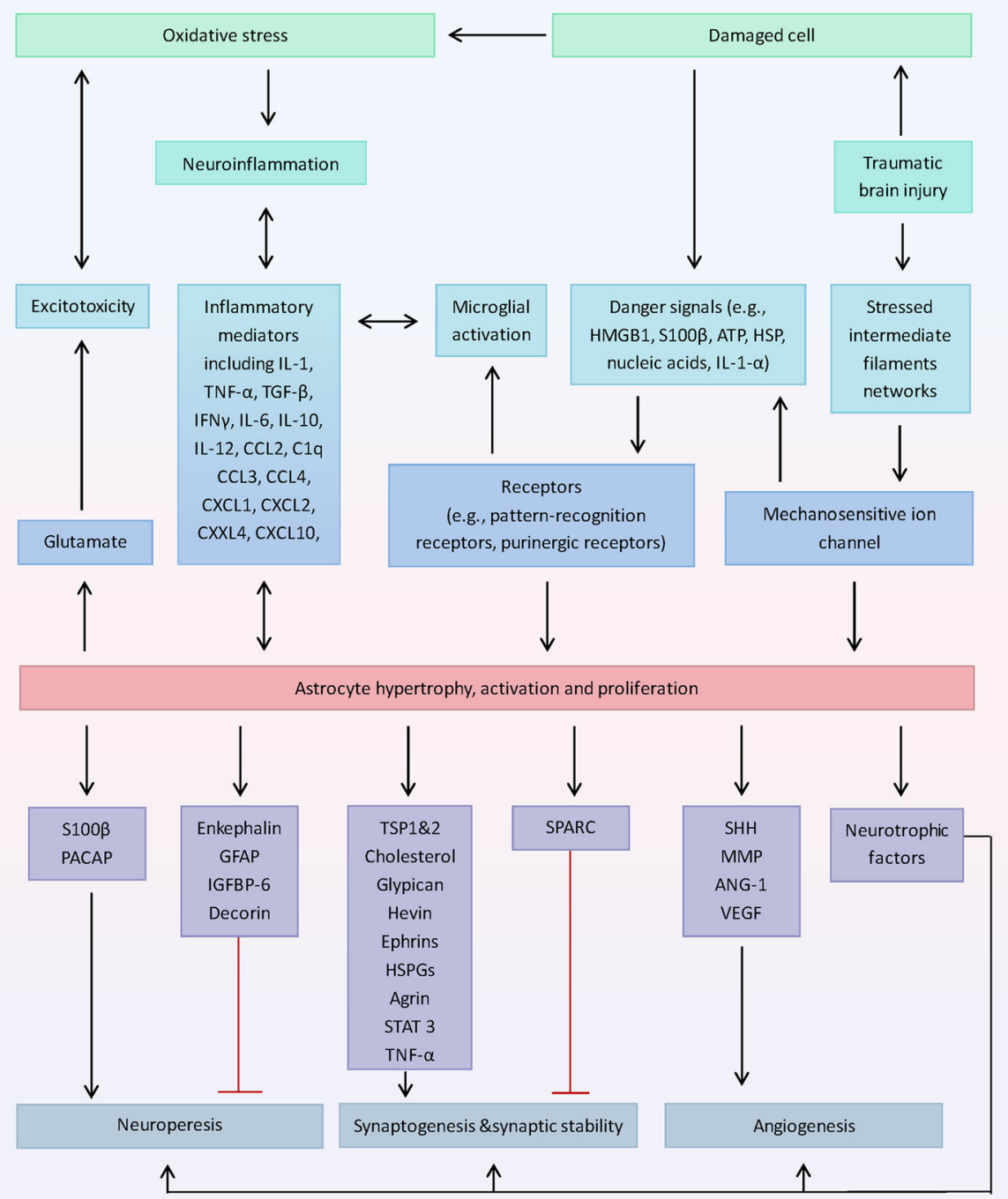

Fig. 3 Potential therapeutic targets regarding astrocyte-derived molecules following TBI. Following TBI, damaged cells release danger signals. And stressed intermediate filaments networks within astrocytes activate ion influx through the mechanosensitive ion channel, resulting in the further release of danger signals. These signals serve to activate neuroglia and induce a robust sterile immune reaction and other secondary TBI pathogenesis. Reactive astrocytes secrete a wide range of factors that affect neurogenesis, synaptogenesis and synaptic stability, and angiogenesis, which may represent the therapeutic targets. Modulating the maladaptive microenvironment caused by neuroinflammation, excitotoxicity and oxidative stress post-TBI is also a considerable therapeutic strategy. ANG-1, angiopoietin-1; CCL, chemokine (C-C motif) ligand; CXCL, chemokine (C-X-C motif) ligand; GFAP, glial fibrillary acidic protein; HMGB1, high mobility group protein B1; HSP, heat shock proteins; HSPGs, heparan sulfate proteoglycans; IFN, interferon; IGFBP-6, insulin-like growth factor binding protein 6; IL, interleukin; MMP, matrix metalloprotein; PACAP, pituitary adenylate cyclase-activating peptide; SHH, sonic hedgehog; SPARC, secreted protein acidic and rich in cysteine; STAT3, signal transducer and activator of transcription-3; TBI, traumatic brain injury; TGF- $\beta$, transforming growth factor- $\beta$; TNF, tumor necrosis factor; TSP, thrombospondin; VEGF, vascular endothelial growth factor

reactive astrogliosis does not have a satisfying curative effect, whereas selectively stimulating the beneficial astrocyte-derived molecules while attenuating the deleterious ones based on the spatiotemporal-environment represents a promising astrocyte-targeting therapeutic strategy. As far, there are a number of related animal experiments that provide some novel therapeutic targets for the pharmacotherapy of TBI, but related clinical trials are rare and the existing ones have failed to show promise for long-term prognosis. Future research should focus more strictly on distinguishing the various functions of astrocyte-derived molecules in a clear subtype, region, and stage of TBI. In addition, more clinical trials concerning astrocyte-targeting therapy are warranted. 


\section{Abbreviations}

ADAM-10: a distintegrin and metalloproteinase-10; AMPA: $\alpha$-amino-3hydroxy-5-methyl-4-isoxazolepropionic acid; ANG-1: Angiopoietin-1; APOE: Apolipoprotein E; AQP4: Aquaporin-4; BBB: Blood-brain barrier; CCL: Chemokine (C-C motif) ligand; CGMP: Cyclic guanosine; CNS: Central nervous system; CO: Carbon monoxide; CSPGs: Chondroitin sulfate proteoglycans; CXCL: Chemokine (C-X-C motif) ligand; CypA: Cyclophilin A; ECM: Extracellular matrix; ETs: Endothelins; GDNF: Glial-derived neurotrophic factor; GFAP: Glial fibrillary acidic protein; HSPGs: Heparan sulfate proteoglycans; IFN: Interferon; IGF-1: Insulin-like growth factor-1; IL: Interleukin; MMP: Matrix metalloprotein; NFKB: Nuclear factor-kB; NMDA: N-methyl-D-aspartate; NO: Nitric oxide; PNNs: Perineuronal nets; RA: Retinoic acid; S1P: Sphingosine 1-phosphate; S1PR: S1P receptor; SHH: Sonic hedgehog; SPARC: Secreted protein acidic and rich in cysteine; STAT3: Signal transducer and activator of transcription-3; TBI: Traumatic brain injury; TGF- $\beta$ : Transforming growth factor- $\beta$; TJ: Tight junction; TNF: Tumor necrosis factor; TSP: Thrombospondin; VEGF: Vascular endothelial growth factor; ZO: Zonula occluden

\section{Authors' contributions}

All the authors participated in analyzing and discussing the literature, commenting on and approving the manuscript. AWS supervised the research, led the discussion, wrote and revised the manuscript. All authors read and approved the final manuscript.

\section{Funding}

This work was funded by China Postdoctoral Science Foundation (2017M612010) and National Natural Science Foundation of China (81701144).

\section{Availability of data and materials}

Not applicable.

\section{Ethics approval and consent to participate}

Not applicable.

\section{Consent for publication}

Not applicable.

\section{Competing interests}

The authors declare that they have no competing interests.

\section{Author details}

'Department of Surgical Oncology, The Second Affiliated Hospital, Zhejiang University School of Medicine, No. 88, Jiefang Road, Zhejiang 310009, Hangzhou, China. ${ }^{2}$ Department of Neurosurgery, The Second Affiliated Hospital, School of Medicine, Zhejiang University, Province, Zhejiang 310009, Hangzhou, China. ${ }^{3}$ State Key Laboratory for Diagnosis and Treatment of Infectious Diseases, Collaborative Innovation Center for Diagnosis and Treatment of Infectious Diseases, The First Affiliated Hospital, College of Medicine, Zhejiang University, Zhejiang, Hangzhou, China.

Received: 19 December 2019 Accepted: 6 March 2020

Published online: 15 April 2020

\section{References}

1. Kardos J, et al. The nature of early astroglial protection-Fast activation and signaling. Prog Neurobiol. 2017;153:86-99.

2. GBD 2016 Traumatic Brain Injury and Spinal Cord Injury Collaborators. Global, regional, and national burden of traumatic brain injury and spinal cord injury, 1990-2016: a systematic analysis for the Global Burden of Disease Study 2016. Lancet Neurol. 2019;18(1):56-87.

3. Maas AIR, et al. Traumatic brain injury: integrated approaches to improve prevention, clinical care, and research. Lancet Neurol. 2017;16(12):987-1048.

4. An C, et al. Severity-Dependent Long-Term Spatial Learning-Memory Impairment in a Mouse Model of Traumatic Brain Injury. Transl Stroke Res. 2016:7(6):512-20.

5. Cooper DJ, et al. Effect of Early Sustained Prophylactic Hypothermia on Neurologic Outcomes Among Patients With Severe Traumatic Brain Injury: The POLAR Randomized Clinical Trial. JAMA. 2018;320(21):2211-20.
6. Dang B, et al. Rehabilitation Treatment and Progress of Traumatic Brain Injury Dysfunction. Neural Plast. 2017;2017:1582182.

7. Roozenbeek B, Maas Al, Menon DK. Changing patterns in the epidemiology of traumatic brain injury. Nat Rev Neurol. 2013:9(4):231-6.

8. Khaksari M, Soltani Z, Shahrokhi N. Effects of Female Sex Steroids Administration on Pathophysiologic Mechanisms in Traumatic Brain Injury. Transl Stroke Res. 2018;9(4):393-416.

9. Colangelo AM, et al. Targeting reactive astrogliosis by novel biotechnological strategies. Biotechnol Adv. 2012;30(1):261-71.

10. Arbo BD, Bennetti F, Ribeiro MF. Astrocytes as a target for neuroprotection: Modulation by progesterone and dehydroepiandrosterone. Prog Neurobiol. 2016;144:27-47.

11. Shields J, et al. Therapeutic targeting of astrocytes after traumatic brain injury. Transl Stroke Res. 2011;2(4):633-42.

12. Sofroniew MV, Vinters HV. Astrocytes: biology and pathology. Acta Neuropathol. 2010;119(1):7-35.

13. Pu H, et al. Repetitive and Prolonged Omega-3 Fatty Acid Treatment After Traumatic Brain Injury Enhances Long-Term Tissue Restoration and Cognitive Recovery. Cell Transplant. 2017;26(4):555-69.

14. Wu Y, et al. Implantation of Brain-Derived Extracellular Matrix Enhances Neurological Recovery after Traumatic Brain Injury. Cell Transplant. 2017; 26(7):1224-34.

15. Perez EJ, et al. Enhanced astrocytic d-serine underlies synaptic damage after traumatic brain injury. J Clin Invest. 2017;127(8):3114-25.

16. Furman $\mathrm{J}$, et al. Blockade of Astrocytic Calcineurin/NFAT Signaling Helps to Normalize Hippocampal Synaptic Function and Plasticity in a Rat Model of Traumatic Brain Injury. J Neurosci. 2016;36(5):1502-15.

17. Warren KM, Reeves TM, Phillips LL. MT5-MMP, ADAM-10, and N-cadherin act in concert to facilitate synapse reorganization after traumatic brain injury. J Neurotrauma. 2012;29(10):1922-40

18. Tyzack $G E$, et al. Astrocyte response to motor neuron injury promotes structural synaptic plasticity via STAT3-regulated TSP-1 expression. Nat Commun. 2014;5:4294

19. de la Tremblaye PB, et al. Elucidating opportunities and pitfalls in the treatment of experimental traumatic brain injury to optimize and facilitate clinical translation. Neurosci Biobehav Rev. 2018:85:160-75.

20. Lee SW, et al. The role of microglial inflammasome activation in pyroptotic cell death following penetrating traumatic brain injury. J Neuroinflammation. 2019;16(1):27.

21. Hostenbach S, et al. The pathophysiological role of astrocytic endothelin-1. Prog Neurobiol. 2016;144:88-102.

22. Ichkova A, et al. Vascular impairment as a pathological mechanism underlying long-lasting cognitive dysfunction after pediatric traumatic brain injury. Neurochem Int. 2017;111:93-102.

23. Hayes JP, et al. Mild traumatic brain injury is associated with reduced cortical thickness in those at risk for Alzheimer's disease. Brain. 2017;140(3):813-25.

24. Lin $C$, et al. Melatonin attenuates traumatic brain injury-induced inflammation: a possible role for mitophagy. J Pineal Res. 2016;61(2): $177-86$.

25. Menge T, et al. Mesenchymal stem cells regulate blood-brain barrier integrity through TIMP3 release after traumatic brain injury. Sci Transl Med. 2012;4(161):161ra150.

26. Wu $\mathrm{H}$, et al. Melatonin attenuates neuronal apoptosis through up-regulation of $\mathrm{K}(+)-\mathrm{Cl}(-)$ cotransporter $\mathrm{KCC} 2$ expression following traumatic brain injury in rats. J Pineal Res. 2016;61(2):241-50.

27. Shlosberg D, et al. Blood-brain barrier breakdown as a therapeutic target in traumatic brain injury. Nat Rev Neurol. 2010;6(7):393-403.

28. Gyoneva S, Ransohoff RM. Inflammatory reaction after traumatic brain injury: therapeutic potential of targeting cell-cell communication by chemokines. Trends Pharmacol Sci. 2015;36(7):471-80.

29. Corps KN, Roth TL, McGavern DB. Inflammation and neuroprotection in traumatic brain injury. JAMA Neurol. 2015;72(3):355-62.

30. Sharma K, Zhang G, Li S. In: So K-F, Xu X-M, editors. Chapter 11 - Astrogliosis and Axonal Regeneration. Neural Regeneration. Oxford: Academic Press; 2015. p. $181-96$

31. Jassam YN, et al. Neuroimmunology of Traumatic Brain Injury: Time for a Paradigm Shift. Neuron. 2017;95(6):1246-65.

32. Kumar A, et al. Microglial-derived microparticles mediate neuroinflammation after traumatic brain injury. J Neuroinflammation. 2017;14(1):47.

33. Johnson VE, et al. Mechanical disruption of the blood-brain barrier following experimental concussion. Acta Neuropathol. 2018;135(5):711-26. 
34. Badaut J, Bix GJ. Vascular neural network phenotypic transformation after traumatic injury: potential role in long-term sequelae. Transl Stroke Res. 2014;5(3):394-406

35. Cai W, et al. Pericytes in Brain Injury and Repair After Ischemic Stroke. Trans| Stroke Res. 2017;8(2):107-21.

36. Villapol $\mathrm{S}$, et al. Neurorestoration after traumatic brain injury through angiotensin II receptor blockage. Brain. 2015;138(Pt 11):3299-315.

37. Wennersten A, Holmin S, Mathiesen T. Characterization of Bax and BCl-2 in apoptosis after experimental traumatic brain injury in the rat. Acta Neuropathol. 2003;105(3):281-8.

38. Nirmala JG, Lopus M. Cell death mechanisms in eukaryotes. Cell Biol Toxicol. 2019

39. Chen T, et al. Arc silence aggravates traumatic neuronal injury via mGluR1mediated ER stress and necroptosis. Cell Death Dis. 2020;11(1):4.

40. Degterev A, Ofengeim D, Yuan J. Targeting RIPK1 for the treatment of human diseases. Proc Natl Acad Sci U S A. 2019;116(20):9714-22.

41. Bao Z, et al. Silencing of A20 Aggravates Neuronal Death and Inflammation After Traumatic Brain Injury: A Potential Trigger of Necroptosis. Front Mol Neurosci. 2019;12:222.

42. Royce GH, Brown-Borg HM, Deepa SS. The potential role of necroptosis in inflammaging and aging. Geroscience. 2019;41(6):795-811.

43. Chen J, et al. Molecular Insights into the Mechanism of Necroptosis: The Necrosome As a Potential Therapeutic Target. Cells. 2019:8(12).

44. Zhang $X$, et al. Bench-to-bedside review: Apoptosis/programmed cell death triggered by traumatic brain injury. Crit Care. 2005;9(1):66-75.

45. Yang Z, Wang KK. Glial fibrillary acidic protein: from intermediate filament assembly and gliosis to neurobiomarker. Trends Neurosci. 2015;38(6):364-74.

46. Sofroniew MV. Astrocyte barriers to neurotoxic inflammation. Nat Rev Neurosci. 2015;16(5):249-63.

47. Rothstein JD, et al. Knockout of glutamate transporters reveals a major role for astroglial transport in excitotoxicity and clearance of glutamate. Neuron. 1996;16(3):675-86

48. Anderson CM, Swanson RA. Astrocyte glutamate transport: review of properties, regulation, and physiological functions. Glia. 2000;32(1):1-14.

49. Zou J, et al. Glutamine synthetase down-regulation reduces astrocyte protection against glutamate excitotoxicity to neurons. Neurochem Int. 2010;56(4):577-84

50. Ye ZC, et al. Functional hemichannels in astrocytes: a novel mechanism of glutamate release. J Neurosci. 2003;23(9):3588-96.

51. Slemmer JE, et al. Antioxidants and free radical scavengers for the treatment of stroke, traumatic brain injury and aging. Curr Med Chem. 2008: 15(4):404-14.

52. Dringen R, Gutterer JM, Hirrlinger J. Glutathione metabolism in brain metabolic interaction between astrocytes and neurons in the defense against reactive oxygen species. Eur J Biochem. 2000;267(16):4912-6.

53. Magistretti PJ, Pellerin L. Cellular mechanisms of brain energy metabolism and their relevance to functional brain imaging. Philos Trans R Soc Lond B Biol Sci. 1999:354(1387):1155-63.

54. Danbolt NC. Glutamate uptake. Prog Neurobiol. 2001;65(1):1-105.

55. Magistretti PJ. Neuron-glia metabolic coupling and plasticity. J Exp Biol. 2006;209(Pt 12):2304-11.

56. Jayakumar AR, Norenberg MD. The $\mathrm{Na}-\mathrm{K}-\mathrm{Cl}$ Co-transporter in astrocyte swelling. Metab Brain Dis. 2010;25(1):31-8.

57. LANG F, et al. Functional Significance of Cell Volume Regulatory Mechanisms. Physiol Rev. 1998;78(1):247-306.

58. Walz W. Role of astrocytes in the clearance of excess extracellular potassium. Neurochem Int. 2000;36(4-5):291-300.

59. Kofuji $P$, Newman EA. Potassium buffering in the central nervous system. Neuroscience. 2004;129(4):1045-56

60. Zhai X, et al. Astrocytes Regulate Angiogenesis Through the Jagged1Mediated Notch1 Pathway After Status Epilepticus. Mol Neurobiol. 2016; 53(9):5893-901.

61. Baldwin KT, Eroglu C. Molecular mechanisms of astrocyte-induced synaptogenesis. Curr Opin Neurobiol. 2017;45:113-20.

62. Muthukumar AK, Stork T, Freeman MR. Activity-dependent regulation of astrocyte GAT levels during synaptogenesis. Nat Neurosci. 2014;17(10):1340-50.

63. Stogsdill JA, et al. Astrocytic neuroligins control astrocyte morphogenesis and synaptogenesis. Nature. 2017;551(7679):192-7.

64. Robinson C, Apgar C, Shapiro LA. Astrocyte Hypertrophy Contributes to Aberrant Neurogenesis after Traumatic Brain Injury. Neural Plast. 2016;2016:1347987.

65. Farina C, Aloisi F, Meinl E. Astrocytes are active players in cerebral innate immunity. Trends Immunol. 2007;28(3):138-45
66. Shastri A, Bonifati DM, Kishore U. Innate immunity and neuroinflammation. Mediators Inflamm. 2013:2013:342931.

67. Ransohoff RM, Brown MA. Innate immunity in the central nervous system. J Clin Invest. 2012;122(4):1164-71.

68. Sofroniew MV. Molecular dissection of reactive astrogliosis and glial scar formation. Trends Neurosci. 2009:32(12):638-47.

69. Fujita $T$, et al. Cellular dynamics of macrophages and microglial cells in reaction to stab wounds in rat cerebral cortex. Acta Neurochir (Wien). 1998; 140(3):275-9.

70. Di Giovanni S, et al. Cell cycle inhibition provides neuroprotection and reduces glial proliferation and scar formation after traumatic brain injury. Proc Natl Acad Sci U S A. 2005;102(23):8333-8.

71. Susarla BT, et al. Temporal patterns of cortical proliferation of glial cell populations after traumatic brain injury in mice. ASN Neuro. 2014;6(3):159-70.

72. Murakami K, et al. Subarachnoid Hemorrhage Induces Gliosis and Increased Expression of the Pro-inflammatory Cytokine High Mobility Group Box 1 Protein. Transl Stroke Res. 2011;2(1):72-9.

73. Peng L, Parpura V, Verkhratsky A. EDITORIAL Neuroglia as a Central Element of Neurological Diseases: An Underappreciated Target for Therapeutic Intervention. Curr Neuropharmacol. 2014;12(4):303-7.

74. Karimi-Abdolrezaee S, Billakanti R. Reactive astrogliosis after spinal cord injury-beneficial and detrimental effects. Mol Neurobiol. 2012;46(2):251-64.

75. Burda JE, Sofroniew MV. Reactive Gliosis and the Multicellular Response to CNS Damage and Disease. Neuron. 2014;81(2):229-48.

76. Cregg JM, et al. Functional regeneration beyond the glial scar. Exp Neurol. 2014;253:197-207.

77. Voskuhl RR, et al. Reactive astrocytes form scar-like perivascular barriers to leukocytes during adaptive immune inflammation of the CNS. J Neurosci. 2009;29(37):11511-22.

78. Michinaga S, Koyama Y. Dual Roles of Astrocyte-Derived Factors in Regulation of Blood-Brain Barrier Function after Brain Damage. Int J Mol Sci. 2019:20(3).

79. Burda JE, Bernstein AM, Sofroniew MV. Astrocyte roles in traumatic brain injury. Exp Neurol. 2016;275(Pt 3):305-15.

80. Sweeney MD, Sagare AP, Zlokovic BV. Blood-brain barrier breakdown in Alzheimer disease and other neurodegenerative disorders. Nat Rev Neurol. 2018;14(3):133-50.

81. Jessen NA, et al. The Glymphatic System: A Beginner's Guide. Neurochem Res. 2015:40(12):2583-99.

82. Louveau A, et al. Understanding the functions and relationships of the glymphatic system and meningeal lymphatics. J Clin Invest. 2017:127(9):3210-9.

83. Garber $C$, et al. Astrocytes decrease adult neurogenesis during virus-induced memory dysfunction via IL-1. Nat Immunol. 2018;19(2):151-61.

84. Tsai HH, et al. Regional astrocyte allocation regulates CNS synaptogenesis and repair. Science. 2012;337(6092):358-62.

85. Vignoli B, et al. Peri-Synaptic Glia Recycles Brain-Derived Neurotrophic Factor for LTP Stabilization and Memory Retention. Neuron. 2016;92(4): 873-87.

86. Zhou Y, et al. Advance of Stem Cell Treatment for Traumatic Brain Injury. Front Cell Neurosci. 2019;13:301.

87. Papa M, et al. Astrocyte-neuron interplay in maladaptive plasticity. Neurosci Biobehav Rev. 2014;42:35-54.

88. Song H, Stevens CF, Gage FH. Astroglia induce neurogenesis from adult neural stem cells. Nature. 2002:417(6884):39-44.

89. Kleindienst $A$, et al. Enhanced hippocampal neurogenesis by intraventricular S100B infusion is associated with improved cognitive recovery after traumatic brain injury. J Neurotrauma. 2005;22(6):645-55.

90. Hinkle DA, et al. GFAP and S100beta expression in the cortex and hippocampus in response to mild cortical contusion. J Neurotrauma. 1997; 14(10):729-38.

91. Choi YK. Role of Carbon Monoxide in Neurovascular Repair Processing. Biomol Ther (Seoul). 2018;26(2):93-100.

92. Seri $B$, et al. Astrocytes give rise to new neurons in the adult mammalian hippocampus. J Neurosci. 2001;21(18):7153-60.

93. van Landeghem FK, et al. Cellular localization of pituitary adenylate cyclaseactivating peptide (PACAP) following traumatic brain injury in humans. Acta Neuropathol. 2007:113(6):683-93.

94. Crupi R, et al. Co-Ultramicronized Palmitoylethanolamide/Luteolin Promotes Neuronal Regeneration after Spinal Cord Injury. Front Pharmacol. 2016;7(47)

95. Gao X, Chen J. Conditional knockout of brain-derived neurotrophic factor in the hippocampus increases death of adult-born immature neurons following traumatic brain injury. J Neurotrauma. 2009;26(8):1325-35. 
96. Amorini AM, et al. Severity of experimental traumatic brain injury modulates changes in concentrations of cerebral free amino acids. J Cell Mol Med. 2017;21(3):530-42.

97. Wilhelmsson $U$, et al. The role of GFAP and vimentin in learning and memory. Biol Chem. 2019;400(9):1147-56.

98. Wilhelmsson $U$, et al. Absence of glial fibrillary acidic protein and vimentin prevents hypertrophy of astrocytic processes and improves post-traumatic regeneration. J Neurosci. 2004;24(21):5016-21.

99. de Pablo $Y$, et al. Intermediate filaments are important for astrocyte response to oxidative stress induced by oxygen-glucose deprivation and reperfusion. Histochem Cell Biol. 2013;140(1):81-91.

100. Wang X, Messing A, David S. Axonal and Nonneuronal Cell Responses to Spinal Cord Injury in Mice Lacking Glial Fibrillary Acidic Protein. Exp Neurol. 1997;148(2):568-76.

101. Prozorovski T, et al. Sirt1 contributes critically to the redox-dependent fate of neural progenitors. Nat Cell Biol. 2008;10(4):385-94.

102. Viviani $B$, et al. Interleukin-1 beta enhances NMDA receptor-mediated intracellular calcium increase through activation of the Src family of kinases. J Neurosci. 2003:23(25):8692-700.

103. Vezzani A, Baram TZ. New roles for interleukin-1 Beta in the mechanisms of epilepsy. Epilepsy Curr. 2007;7(2):45-50.

104. Barkho BZ, et al. Identification of astrocyte-expressed factors that modulate neural stem/progenitor cell differentiation. Stem Cells Dev. 2006;15(3):407-21.

105. Ullian EM, et al. Control of synapse number by glia. Science. 2001;291(5504): 657-61.

106. Pfrieger FW, Barres BA. New views on synapse-glia interactions. Curr Opin Neurobiol. 1996;6(5):615-21.

107. Nieweg K, Schaller H, Pfrieger FW. Marked differences in cholesterol synthesis between neurons and glial cells from postnatal rats. J Neurochem. 2009:109(1):125-34.

108. Pfrieger FW. Roles of glial cells in synapse development. Cell Mol Life Sci. 2009;66(13):2037-47.

109. Buss A, et al. Growth-modulating molecules are associated with invading Schwann cells and not astrocytes in human traumatic spinal cord injury. Brain. 2007;130(Pt 4):940-53.

110. Ullian EM, Christopherson KS, Barres BA. Role for glia in synaptogenesis. Glia. 2004:47(3):209-16

111. Falo MC, Reeves TM, Phillips LL. Agrin expression during synaptogenesis induced by traumatic brain injury. J Neurotrauma. 2008;25(7):769-83.

112. Bali $\mathrm{N}$, et al. Progesterone antagonism of neurite outgrowth depends on microglial activation via Pgrmc1/S2R. Endocrinology. 2013;154(7):2468-80.

113. Herrmann JE, et al. STAT3 is a critical regulator of astrogliosis and scar formation after spinal cord injury. J Neurosci. 2008;28(28):7231-43.

114. Okada S, et al. Conditional ablation of Stat3 or Socs3 discloses a dual role for reactive astrocytes after spinal cord injury. Nat Med. 2006;12(7):829-34.

115. Christopherson KS, et al. Thrombospondins are astrocyte-secreted proteins that promote CNS synaptogenesis. Cell. 2005;120(3):421-33.

116. Kucukdereli $\mathrm{H}$, et al. Control of excitatory CNS synaptogenesis by astrocytesecreted proteins Hevin and SPARC. Proc Natl Acad Sci. 2011:108(32):E440-9.

117. Albrecht D, et al. SPARC prevents maturation of cholinergic presynaptic terminals. Mol Cell Neurosci. 2012;49(3):364-74.

118. Jones EV, et al. Astrocytes control glutamate receptor levels at developing synapses through SPARC-beta-integrin interactions. J Neurosci. 2011;31(11): 4154-65.

119. Allen NJ, et al. Astrocyte glypicans 4 and 6 promote formation of excitatory synapses via GluA1 AMPA receptors. Nature. 2012;486:410.

120. Fuentes-Medel $Y$, et al. Integration of a Retrograde Signal during Synapse Formation by Glia-Secreted TGF- $\beta$ Ligand. Current Biology. 2012;22(19): 1831-8.

121. Diniz LP, et al. Astrocyte-induced synaptogenesis is mediated by transforming growth factor beta signaling through modulation of D-serine levels in cerebral cortex neurons. J Biol Chem. 2012;287(49):41432-45.

122. Gómez-Casati ME, et al. Nonneuronal cells regulate synapse formation in the vestibular sensory epithelium via erbB-dependent BDNF expression. Proc Natl Acad Sci. 2010;107(39):17005-10.

123. Garrett AM, Weiner JA. Control of CNS synapse development by \{gamma\}protocadherin-mediated astrocyte-neuron contact. J Neurosci. 2009;29(38): 11723-31.

124. Jeong SR, et al. Hepatocyte growth factor reduces astrocytic scar formation and promotes axonal growth beyond glial scars after spinal cord injury. Exp Neurol. 2012;233(1):312-22
125. Yi JH, et al. Alterations in sulfated chondroitin glycosaminoglycans following controlled cortical impact injury in mice. J Comp Neurol. 2012;520(15):3295-313.

126. Buss A, et al. Gradual loss of myelin and formation of an astrocytic scar during Wallerian degeneration in the human spinal cord. Brain. 2004;127(Pt 1):34-44

127. Li L, et al. Toll-like receptor 9 antagonism modulates astrocyte function and preserves proximal axons following spinal cord injury. Brain Behav Immun. 2019;80:328-43.

128. Bradbury EJ, et al. Chondroitinase $A B C$ promotes functional recovery after spinal cord injury. Nature. 2002;416(6881):636-40.

129. Wang D, Fawcett J. The perineuronal net and the control of CNS plasticity. Cell Tissue Res. 2012;349(1):147-60

130. Sorg BA, et al. Casting a Wide Net: Role of Perineuronal Nets in Neural Plasticity. J Neurosci. 2016;36(45):11459-68.

131. Shen $Y$, et al. PTPsigma is a receptor for chondroitin sulfate proteoglycan, an inhibitor of neural regeneration. Science. 2009;326(5952):592-6.

132. Dickendesher TL, et al. NgR1 and NgR3 are receptors for chondroitin sulfate proteoglycans. Nat Neurosci. 2012;15(5):703-12.

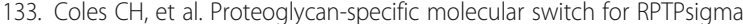
clustering and neuronal extension. Science. 2011;332(6028):484-8

134. Brown JM, et al. A sulfated carbohydrate epitope inhibits axon regeneration after injury. Proc Natl Acad Sci U S A. 2012;109(13):4768-73.

135. Carulli $D$, et al. Animals lacking link protein have attenuated perineuronal nets and persistent plasticity. Brain. 2010;133(Pt 8):2331-47.

136. Treloar HB, et al. Tenascin-C is an inhibitory boundary molecule in the developing olfactory bulb. J Neurosci. 2009;29(30):9405-16.

137. Deller $T$, et al. Up-regulation of astrocyte-derived tenascin-C correlates with neurite outgrowth in the rat dentate gyrus after unilateral entorhinal cortex lesion. Neuroscience. 1997;81(3):829-46.

138. Kim HJ, et al. Elevation of hippocampal MMP-3 expression and activity during trauma-induced synaptogenesis. Exp Neurol. 2005;192(1):60-72.

139. Falo MC, et al. Matrix metalloproteinase-3 expression profile differentiates adaptive and maladaptive synaptic plasticity induced by traumatic brain injury. J Neurosci Res. 2006:84(4):768-81.

140. Albensi BC. Models of brain injury and alterations in synaptic plasticity. J Neurosci Res. 2001:65(4):279-83.

141. Allen NJ. Role of glia in developmental synapse formation. Curr Opin Neurobiol. 2013;23(6):1027-33.

142. Clarke LE, Barres BA. Emerging roles of astrocytes in neural circuit development. Nat Rev Neurosci. 2013;14(5):311-21.

143. Cuzzocrea S, et al. Sphingosine 1-Phosphate Receptor Subtype 1 as a Therapeutic Target for Brain Trauma. J Neurotrauma. 2018;35(13):1452-66.

144. Yew WP, et al. Early treatment with minocycline following stroke in rats improves functional recovery and differentially modifies responses of periinfarct microglia and astrocytes. J Neuroinflammation. 2019;16(1):6.

145. Rodriguez-Manzaneque JC, et al. Thrombospondin-1 suppresses spontaneous tumor growth and inhibits activation of matrix metalloproteinase-9 and mobilization of vascular endothelial growth factor. Proc Natl Acad Sci U S A. 2001:98(22):12485-90.

146. Pan $\mathrm{H}$, et al. The absence of Nrf2 enhances NF-kappaB-dependent inflammation following scratch injury in mouse primary cultured astrocytes. Mediators Inflamm. 2012;2012:217580

147. Hubbard JA, Szu JI, Binder DK. The role of aquaporin-4 in synaptic plasticity, memory and disease. Brain Res Bull. 2018;136:118-29.

148. Ashkar S, et al. Eta-1 (osteopontin): an early component of type-1 (cellmediated) immunity. Science. 2000;287(5454):860-4.

149. Zhang C, Chen J, Lu H. Expression of aquaporin-4 and pathological characteristics of brain injury in a rat model of traumatic brain injury. Mol Med Rep. 2015;12(5):7351-7.

150. Giulian D, et al. Interleukin-1 injected into mammalian brain stimulates astrogliosis and neovascularization. J Neurosci. 1988;8(7):2485-90.

151. Asher RA, et al. Neurocan is upregulated in injured brain and in cytokinetreated astrocytes. J Neurosci. 2000;20(7):2427-38.

152. Kwok JC, et al. Extracellular matrix and perineuronal nets in CNS repair. Dev Neurobiol. 2011;71(11):1073-89.

153. Fawcett JW, Oohashi T, Pizzorusso T. The roles of perineuronal nets and the perinodal extracellular matrix in neuronal function. Nat Rev Neurosci. 2019; 20(8):451-65.

154. Frischknecht $R$, et al. Brain extracellular matrix affects AMPA receptor lateral mobility and short-term synaptic plasticity. Nat Neurosci. 2009;12(7):897-904. 
155. Pyka M, et al. Chondroitin sulfate proteoglycans regulate astrocytedependent synaptogenesis and modulate synaptic activity in primary embryonic hippocampal neurons. Eur J Neurosci. 2011;33(12):2187-202.

156. Beattie EC, et al. Control of synaptic strength by glial TNFalpha. Science. 2002;295(5563):2282-5.

157. Stellwagen D, Malenka RC. Synaptic scaling mediated by glial TNF-alpha. Nature. 2006;440(7087):1054-9.

158. Steinmetz CC, Turrigiano GG. Tumor necrosis factor-alpha signaling maintains the ability of cortical synapses to express synaptic scaling. J Neurosci. 2010;30(44):14685-90.

159. Sofroniew MV. Reactive astrocytes in neural repair and protection. Neuroscientist. 2005;11(5):400-7.

160. Bush TG, et al. Leukocyte infiltration, neuronal degeneration, and neurite outgrowth after ablation of scar-forming, reactive astrocytes in adult transgenic mice. Neuron. 1999;23(2):297-308.

161. Faulkner JR, et al. Reactive astrocytes protect tissue and preserve function after spinal cord injury. J Neurosci. 2004;24(9):2143-55.

162. Myer DJ, et al. Essential protective roles of reactive astrocytes in traumatic brain injury. Brain. 2006;129(Pt 10):2761-72.

163. Murai KK, Pasquale EB. Eph receptors and ephrins in neuron-astrocyte communication at synapses. Glia. 2011;59(11):1567-78.

164. Filosa A, et al. Neuron-glia communication via EphA4/ephrin-A3 modulates LTP through glial glutamate transport. Nat Neurosci. 2009;12(10):1285-92.

165. Gupta RK, Prasad S. Early down regulation of the glial Kir4.1 and GLT-1 expression in pericontusional cortex of the old male mice subjected to traumatic brain injury. Biogerontology. 2013;14(5):531-41.

166. Klein $\mathrm{P}$, et al. Commonalities in epileptogenic processes from different acute brain insults: Do they translate? Epilepsia. 2018;59(1):37-66.

167. Buritica $E$, et al. Changes in calcium-binding protein expression in human cortical contusion tissue. J Neurotrauma. 2009;26(12):2145-55.

168. Kim SY, et al. A potential role for glia-derived extracellular matrix remodeling in postinjury epilepsy. J Neurosci Res. 2016;94(9):794-803.

169. Volman V, Bazhenov M, Sejnowski TJ. Divide and conquer: functional segregation of synaptic inputs by astrocytic microdomains could alleviate paroxysmal activity following brain trauma. PLoS Comput Biol. 2013;9(1): e1002856.

170. Akassoglou K, et al. Astrocyte-specific but not neuron-specific transmembrane TNF triggers inflammation and degeneration in the central nervous system of transgenic mice. J Immunol. 1997;158(1):438-45.

171. Tuttolomondo A, Pecoraro R, Pinto A. Studies of selective TNF inhibitors in the treatment of brain injury from stroke and trauma: a review of the evidence to date. Drug Des Devel Ther. 2014;8:2221-38.

172. Boison D. The adenosine kinase hypothesis of epileptogenesis. Prog Neurobiol. 2008;84(3):249-62.

173. Bloom GS. Amyloid- $\beta$ and tau: the trigger and bullet in Alzheimer disease pathogenesis. JAMA Neurol. 2014;71(4):505-8.

174. McKee $A C$, et al. The spectrum of disease in chronic traumatic encephalopathy. Brain. 2013;136(Pt 1):43-64

175. Chen $\mathrm{H}$, et al. Head injury and amyotrophic lateral sclerosis. Am J Epidemiol. 2007;166(7):810-6.

176. McKee AC, et al. Chronic traumatic encephalopathy in athletes: progressive tauopathy after repetitive head injury. J Neuropathol Exp Neurol. 2009;68(7): 709-35

177. Luissint AC, et al. Tight junctions at the blood brain barrier: physiological architecture and disease-associated dysregulation. Fluids Barriers CNS. 2012; 9(1):23.

178. Burek, M., et al., Hypoxia-Induced MicroRNA-212/132 Alter Blood-Brain Barrier Integrity Through Inhibition of Tight Junction-Associated Proteins in Human and Mouse Brain Microvascular Endothelial Cells. Transl Stroke Res, 2019.

179. Brickler TR, et al. Angiopoietin/Tie2 Axis Regulates the Age-at-Injury Cerebrovascular Response to Traumatic Brain Injury. J Neurosci. 2018;38(45): 9618-34.

180. Gurnik S, et al. Angiopoietin-2-induced blood-brain barrier compromise and increased stroke size are rescued by VE-PTP-dependent restoration of Tie2 signaling. Acta Neuropathol. 2016;131(5):753-73.

181. Zhao J, et al. Angiopoietin-1 protects the endothelial cells against advanced glycation end product injury by strengthening cell junctions and inhibiting cell apoptosis. J Cell Physiol. 2015;230(8):1895-905.

182. Alvarez Jl, Katayama T, Prat A. Glial influence on the blood brain barrier. Glia. 2013;61(12):1939-58.
183. Alvarez Jl, et al. The Hedgehog pathway promotes blood-brain barrier integrity and CNS immune quiescence. Science. 2011;334(6063):1727-31.

184. Brilha S, et al. Matrix metalloproteinase-9 activity and a downregulated Hedgehog pathway impair blood-brain barrier function in an in vitro model of CNS tuberculosis. Sci Rep. 2017;7(1):16031.

185. Xia YP, et al. Recombinant human sonic hedgehog protein regulates the expression of ZO-1 and occludin by activating angiopoietin-1 in stroke damage. PLoS One. 2013;8(7):e68891.

186. Igarashi $Y$, et al. Expression of receptors for glial cell line-derived neurotrophic factor (GDNF) and neurturin in the inner blood-retinal barrier of rats. Cell Struct Funct. 2000;25(4):237-41.

187. Shimizu F, et al. Pericyte-derived glial cell line-derived neurotrophic factor increase the expression of claudin- 5 in the blood-brain barrier and the blood-nerve barrier. Neurochem Res. 2012;37(2):401-9.

188. Xiao W, et al. GDNF is involved in the barrier-inducing effect of enteric glial cells on intestinal epithelial cells under acute ischemia reperfusion stimulation. Mol Neurobiol. 2014;50(2):274-89.

189. Mizee MR, et al. Astrocyte-derived retinoic acid: a novel regulator of bloodbrain barrier function in multiple sclerosis. Acta Neuropathol. 2014;128(5): 691-703.

190. Kong $L$, et al. Retinoic acid ameliorates blood-brain barrier disruption following ischemic stroke in rats. Pharmacol Res. 2015;99:125-36.

191. Gille J, et al. Retinoic acid inhibits the regulated expression of vascular cell adhesion molecule-1 by cultured dermal microvascular endothelial cells. J Clin Invest. 1997;99(3):492-500.

192. Bake S, et al. Insulin-Like Growth Factor (IGF)-I Modulates Endothelial BloodBrain Barrier Function in Ischemic Middle-Aged Female Rats. Endocrinology. 2016;157(1):61-9.

193. Bake S, et al. Insulin-like Growth Factor (IGF)-1 treatment stabilizes the microvascular cytoskeleton under ischemic conditions. Exp Neurol. 2019;311: $162-72$

194. Mahley RW, Weisgraber KH, Huang Y. Apolipoprotein E: structure determines function, from atherosclerosis to Alzheimer's disease to AIDS. J Lipid Res. 2009;50(Suppl):S183-8.

195. Nishitsuji K, et al. Apolipoprotein E regulates the integrity of tight junctions in an isoform-dependent manner in an in vitro blood-brain barrier model. J Biol Chem. 2011;286(20):17536-42.

196. Bell RD, et al. Apolipoprotein E controls cerebrovascular integrity via cyclophilin A. Nature. 2012;485(7399):512-6.

197. Cao F, et al. Apolipoprotein E-Mimetic COG1410 Reduces Acute Vasogenic Edema following Traumatic Brain Injury. J Neurotrauma. 2016;33(2):175-82.

198. Teng Z, et al. ApoE Influences the Blood-Brain Barrier Through the NFkappaB/MMP-9 Pathway After Traumatic Brain Injury. Sci Rep. 2017;7(1):6649.

199. Methia N, et al. ApoE deficiency compromises the blood brain barrier especially after injury. Mol Med. 2001;7(12):810-5.

200. Hafezi-Moghadam A, Thomas KL, Wagner DD. ApoE deficiency leads to a progressive age-dependent blood-brain barrier leakage. Am J Physiol Cell Physiol. 2007;292(4):C1256-62.

201. Zheng $M$, et al. ApoE-deficient promotes blood-brain barrier disruption in experimental autoimmune encephalomyelitis via alteration of MMP-9. J Mol Neurosci. 2014;54(2):282-90

202. Pang J, et al. Inhibition of Blood-Brain Barrier Disruption by an Apolipoprotein E-Mimetic Peptide Ameliorates Early Brain Injury in Experimental Subarachnoid Hemorrhage. Transl Stroke Res. 2017;8(3):257-72.

203. Pang J, et al. Apolipoprotein E Exerts a Whole-Brain Protective Property by Promoting M1? Microglia Quiescence After Experimental Subarachnoid Hemorrhage in Mice. Transl Stroke Res. 2018;9(6):654-68.

204. Jiang S, et al. Vascular endothelial growth factors enhance the permeability of the mouse blood-brain barrier. PLoS One. 2014;9(2):e86407.

205. Wu L, et al. Vascular endothelial growth factor aggravates cerebral ischemia and reperfusion-induced blood-brain-barrier disruption through regulating LOC102640519/HOXC13/ZO-1 signaling. Exp Cell Res. 2018;369(2):275-83.

206. Argaw AT, et al. Astrocyte-derived VEGF-A drives blood-brain barrier disruption in CNS inflammatory disease. J Clin Invest. 2012:122(7):2454-68.

207. Kim E, et al. Inhibition of VEGF Signaling Reduces Diabetes-Exacerbated Brain Swelling, but Not Infarct Size, in Large Cerebral Infarction in Mice. Transl Stroke Res. 2018;9(5):540-8.

208. Yang Y, et al. Matrix metalloproteinase-mediated disruption of tight junction proteins in cerebral vessels is reversed by synthetic matrix metalloproteinase inhibitor in focal ischemia in rat. J Cereb Blood Flow Metab. 2007;27(4):697-709. 
209. Liu X, et al. Effects of blockade of ionotropic glutamate receptors on bloodbrain barrier disruption in focal cerebral ischemia. Neurol Sci. 2010;31(6): 699-703.

210. Andras IE, et al. The NMDA and AMPA/KA receptors are involved in glutamate-induced alterations of occludin expression and phosphorylation in brain endothelial cells. J Cereb Blood Flow Metab. 2007;27(8):1431-43.

211. Kim JE, Ryu HJ, Kang TC. Status epilepticus induces vasogenic edema via tumor necrosis factor-alpha/ endothelin-1-mediated two different pathways. PLoS One. 2013;8(9):e74458.

212. Kim JY, et al. ETB receptor-mediated MMP-9 activation induces vasogenic edema via ZO-1 protein degradation following status epilepticus. Neuroscience. 2015;304:355-67.

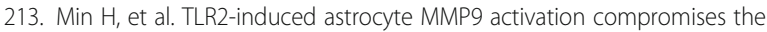
blood brain barrier and exacerbates intracerebral hemorrhage in animal models. Mol Brain. 2015;8:23.

214. Zhang S, et al. Autophagy- and MMP-2/9-mediated Reduction and Redistribution of ZO-1 Contribute to Hyperglycemia-increased Blood-Brain Barrier Permeability During Early Reperfusion in Stroke. Neuroscience. 2018; 377:126-37.

215. Gu Y, et al. Caveolin-1 regulates nitric oxide-mediated matrix metalloproteinases activity and blood-brain barrier permeability in focal cerebral ischemia and reperfusion injury. J Neurochem. 2012;120(1):147-56.

216. Jiang $Z$, et al. Role of nitric oxide synthases in early blood-brain barrier disruption following transient focal cerebral ischemia. PLoS One. 2014;9(3): e93134.

217. Chen $\mathrm{H}$, et al. Baicalin Attenuates Blood-Brain Barrier Disruption and Hemorrhagic Transformation and Improves Neurological Outcome in Ischemic Stroke Rats with Delayed t-PA Treatment: Involvement of ONOO()-MMP-9 Pathway. Transl Stroke Res. 2018;9(5):515-29.

218. Sang H, et al. Early Increased Bradykinin 1 Receptor Contributes to Hemorrhagic Transformation After Ischemic Stroke in Type 1 Diabetic Rats. Transl Stroke Res. 2017:8(6):597-611.

219. Shen $Y H$, Wang $X L$, Wilcken DE. Nitric oxide induces and inhibits apoptosis through different pathways. FEBS Lett. 1998;433(1-2):125-31.

220. Vazana U, et al. Glutamate-Mediated Blood-Brain Barrier Opening: Implications for Neuroprotection and Drug Delivery. J Neurosci. 2016;36(29): 7727-39.

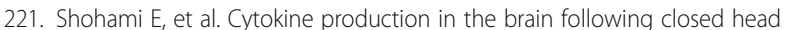
injury: dexanabinol (HU-211) is a novel TNF-alpha inhibitor and an effective neuroprotectant. J Neuroimmunol. 1997;72(2):169-77.

222. Prager B, Spampinato SF, Ransohoff RM. Sphingosine 1-phosphate signaling at the blood-brain barrier. Trends Mol Med. 2015;21(6):354-63.

223. Zuo S, et al. Artesunate Protected Blood-Brain Barrier via Sphingosine 1 Phosphate Receptor 1/Phosphatidylinositol 3 Kinase Pathway After Subarachnoid Hemorrhage in Rats. Mol Neurobiol. 2017;54(2):1213-28.

224. Sun N, et al. Critical Role of the Sphingolipid Pathway in Stroke: a Review of Current Utility and Potential Therapeutic Targets. Transl Stroke Res. 2016; 7(5):420-38

225. Hasegawa $Y$, et al. Role of the sphingosine metabolism pathway on neurons against experimental cerebral ischemia in rats. Transl Stroke Res. 2013:4(5):524-32.

226. Schuhmann MK, et al. Fingolimod (FTY720-P) Does Not Stabilize the BloodBrain Barrier under Inflammatory Conditions in an in Vitro Model. Int J Mol Sci. 2015;16(12):29454-66.

227. Choo AM, et al. Antagonism of purinergic signalling improves recovery from traumatic brain injury. Brain. 2013;136(Pt 1):65-80.

228. Ikonomidou C, Turski L. Why did NMDA receptor antagonists fail clinical trials for stroke and traumatic brain injury? Lancet Neurol. 2002;1 (6):383-6.

229. Barreto $G$, et al. Selective estrogen receptor modulators decrease reactive astrogliosis in the injured brain: effects of aging and prolonged depletion of ovarian hormones. Endocrinology. 2009;150(11):5010-5.

230. Katz PS, et al. Endocannabinoid degradation inhibition improves neurobehavioral function, blood-brain barrier integrity, and neuroinflammation following mild traumatic brain injury. J Neurotrauma. 2015;32(5):297-306.

231. Morris GF, et al. Failure of the competitive N-methyl-D-aspartate antagonist Selfotel (CGS 19755) in the treatment of severe head injury: results of two phase III clinical trials.The Selfotel Investigators. J Neurosurg. 1999;91(5):737-43.

232. Rothstein JD, et al. Beta-lactam antibiotics offer neuroprotection by increasing glutamate transporter expression. Nature. 2005;433(7021):73-7.
233. Fontana AC, et al. Enhancing glutamate transport: mechanism of action of Parawixin1, a neuroprotective compound from Parawixia bistriata spider venom. Mol Pharmacol. 2007;72(5):1228-37.

234. Barron KD, et al. Ultrastructural features of a brain injury model in cat. I. Vascular and neuroglial changes and the prevention of astroglial swelling by a fluorenyl (aryloxy) alkanoic acid derivative (L-644,711). Acta Neuropathol. 1988;75(3):295-307.

235. Kimelberg HK, et al. Brain anti-cytoxic edema agents. Prog Clin Biol Res. 1990;361:363-85.

236. Bhalala $O G$, et al. MicroRNA-21 regulates astrocytic response following spinal cord injury. J Neurosci. 2012;32(50):17935-47.

237. Pan YB, Sun ZL, Feng DF. The Role of MicroRNA in Traumatic Brain Injury. Neuroscience. 2017:367:189-99.

238. Hong $\mathrm{P}$, Jiang M, Li H. Functional requirement of dicer1 and miR-17-5p in reactive astrocyte proliferation after spinal cord injury in the mouse. Glia. 2014;62(12):2044-60

239. Yang $X$, et al. Hypertonic saline maintains coagulofibrinolytic homeostasis following moderatetosevere traumatic brain injury by regulating monocyte phenotype via expression of IncRNAs. Mol Med Rep. 2019;19(2):1083-91.

\section{Publisher's Note}

Springer Nature remains neutral with regard to jurisdictional claims in published maps and institutional affiliations.
Ready to submit your research? Choose BMC and benefit from:

- fast, convenient online submission

- thorough peer review by experienced researchers in your field

- rapid publication on acceptance

- support for research data, including large and complex data types

- gold Open Access which fosters wider collaboration and increased citations

- maximum visibility for your research: over $100 \mathrm{M}$ website views per year

At BMC, research is always in progress.

Learn more biomedcentral.com/submissions 